LEPRA, POLÍTICAS SANITÁRIAS E CONTROLE SOCIAL: ISOLAMENTO E COTIDIANO NA LAZARÓPOLIS SANTO ANTÔNIO DO PRATA, PARÁ

LEPROSY, SANITARY POLICIES AND SOCIAL CONTROL: ISOLATION AND EVERYDAY LIFE IN LAZAROPOLIS SANTO ANTÔNIO DO PRATA, IN PARÁ STATE

Rhuan Carlos dos Santos Lopes

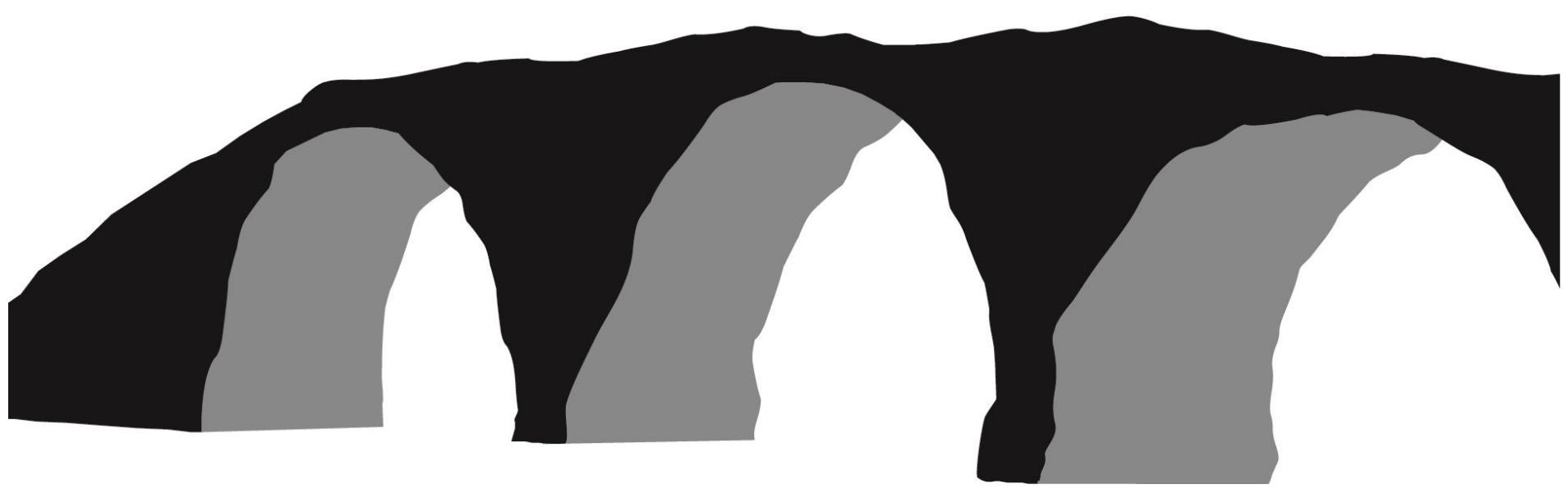




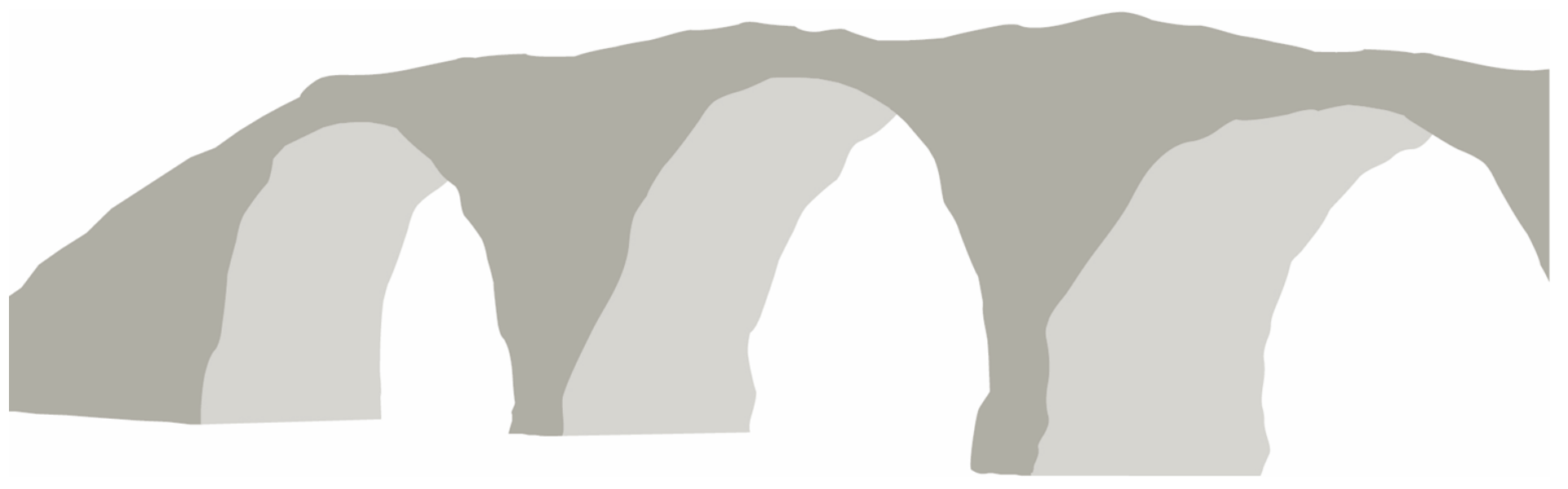

Data de recebimento: 09/02/2018.

Data de aceite: 15/04/2018. 


\title{
LEPRA, POLÍTICAS SANITÁRIAS E CONTROLE SOCIAL: ISOLAMENTO E COTIDIANO NA LAZARÓPOLIS SANTO ANTÔNIO DO PRATA, PARÁ
}

\author{
LEPROSY, SANITARY POLICIES AND SOCIAL CONTROL: ISOLATION AND \\ EVERYDAY LIFE IN LAZAROPOLIS SANTO ANTÔNIO DO PRATA, IN PARÁ \\ STATE
}

\author{
Rhuan Carlos dos Santos Lopes ${ }^{1}$
}

RESUMO

Analiso os remanescentes arquitetônicos da Colônia de Leprosos Santo Antônio do Prata, no estado do Pará, Amazônia brasileira. O debate considera o contexto nacional referente à política de combate à hanseníase, em específico, na primeira metade do século XX. O foco de análise recai sobre a organização espacial, em particular a arquitetura da instituição. Para isso, apliquei modelos de análise morfológicoespacial em dois pavilhões de internamento. Tais informações foram conjugadas com dados etnográficos e históricos. Argumento que a infraestrutura material da instituição foi constituída enquanto tecnologia de poder sobre os corpos dos grupos a ela submetidos, com objetivos de políticas de Estado que tinham como pressuposto o binômio reclusão e exclusão.

Palavras-chave: Arqueologia da Arquitetura, instituição total, hanseníase, Arqueologia Histórica.

\section{RESUMEN}

Analizo los restos arquitectónicos de la Colonia de Leprosos de Santo Antônio do Prata, en el estado de Pará, Amazonía Brasilera. El debate considera el contexto nacional con relación a la política de combate a la enfermedad de Hansen, en particular en la primera mitad del silgo XX. El eje del análisis está en la organización espacial, en particular en la arquitectura de la institución, aplicando modelos de análisis morfológico-espacial en dos pabellones de internación y conjugando la información con datos etnográficos e históricos. Argumento que la infraestructura material de la institución fue constituida como tecnología de poder sobre los cuerpos de los grupos sometidos a ella, con objetivos de políticas de Estado cuyo presupuesto era el binomio de reclusión y exclusión.

Palabras clave: Arqueología de la Arquitectura, institución total, lepra, Arqueología Histórica.

\footnotetext{
${ }^{1}$ Bolsista de Pós-doutorado/CAPES. Programa de Pós-Graduação em Ciências Sociais (PPCIS), Universidade do Estado do Rio de Janeiro (UERJ). Rua São Francisco Xavier, 524, CEP: 20550-900 - 9ª andar, sala 9037, bloco F. Endereço eletrônico: rhuan.c.lopes@gmail.com.
} 


\begin{abstract}
I analyze the architectural remnants of the Leprosy Colony Santo Antônio do Prata, in Pará state, Brazilian Amazon. The debate considers the national context concerning the policy to combat leprosy, especially in the first half of the 20th century. The analysis focuses on the spatial organization, in particular the architecture of the institution. For this, I applied morphological-spatial analysis models in two internment pavilions. Such information was coupled with ethnographic and historical data. I argue that the material infrastructure of this institution was constituted as a technology of power over the bodies of the groups submitted to it, with State policies objectives that had as presupposition the binomial reclusion and exclusion.
\end{abstract}

Keywords: Archeology of Architecture, total institution, leprosy, Historical Archeology. 


\section{INTRODUÇÃO}

No Brasil, nas primeiras décadas do século XX, uma das políticas de Estado assumiu a lepra como problema de saúde pública (Ducatti, 2007). Por todo o país, foram construídas Colônias Agrícolas para segregação de pessoas acometidas pela então chamada lepra, sob o argumento de que essa era melhor maneira de tratá-los e, do mesmo modo, proteger os cidadãos sadios. Efetivamente, segregar os leprosos como medida sanitária incluía o estabelecimento de sistemáticas práticas de domínio, incorporadas à organização e ao cotidiano do leprosário (Monteiro, 2003).

A partir de 1977 foram executadas mudanças na política brasileira de atenção aos portadores de lepra: passou-se a utilizar o termo hanseníase para designar a doença, com o fito de extirpar as representações sociais negativas suscitadas com a designação mais antiga, remanescente de tempos bíblicos (Câmara, 2009). Efetivamente, a substituição das palavras protege momentaneamente o portador da enfermidade frente aos estigmas, na medida em que se entende como outra doença (Barreto et al., 2013).

No Pará, a política iniciada na Primeira República brasileira começou a ser implementada na Colônia Santo Antônio do Prata, localizada no município de Igarapé-Açu, nordeste do estado (Almeida, 2007) (Figura 1). Este local não foi escolhido por acaso, pois ali haviam existido anteriormente outras duas instituições de controle. A primeira, em fins do século XIX, foi o Núcleo Colonial Indígena, formado por dois educandários destinados aos filhos dos Tembé/Tenetehara, que viviam no Vale do Rio Maracanã. Em 1921, o Núcleo foi substituído por um Centro Correcional, que possuiu rápida existência, já que no mesmo ano foi trocado pelo Leprosário do Prata, como o lugar ainda é conhecido até hoje.

A partir disso, neste artigo analiso a configuração espacial e arquitetônica do leprosário, considerando o contexto nacional referente à política de combate à hanseníase, em particular na primeira metade do século XX.

No estudo que desenvolveu sobre a Lazarópolis criada no Prata, Almeida (2007) defendeu que a instituição fez parte do início do programa nacional de internamento compulsório de doentes de hanseníase, acompanhando outros autores que indicam a política sanitária brasileira para lepra com viés eugênico ${ }^{2}$ (Ducatti, 2007; Monteiro, 1998, 2003). Por outro lado, os estudos dedicados às instituições totais voltadas ao controle social da hanseníase são enfáticos ao descreverem o uso da arquitetura como mecanismo integrante do sistema de controle dos pacientes (Câmara, 2009; Monteiro, 2003; French, 1995).

Tendo isto em vista, apresento parte dos resultados da pesquisa arqueológica desenvolvida entre os anos de 2012 e 2016 na atual Vila Santo Antônio do Prata. O foco de análise recai sobre a organização espacial, em particular a arquitetura da instituição. Para isso, aplico modelos de análise morfológico-espacial em dois pavilhões de internamento, nos quais residiam elevado número de pacientes. Tais informações são conjugadas com dados etnográficos e históricos coligidos ao longo da investigação. Assim, argumento que a infraestrutura material do Prata foi constituída enquanto tecnologia de poder sobre os corpos dos grupos a ela submetidos, com objetivos de políticas de Estado que tinham como pressuposto o binômio reclusão e exclusão (Lopes, 2017).

\footnotetext{
${ }^{2}$ Eugenia é definida como a ciência dedica ao aprimoramento racial. No Brasil, entre 1900 e 1940, o debate sobre tal questão incorporou as teorias anglo-saxões, atualizando-o no contexto racial e econômico do país (Cf. Stepan, 2004).
} 
Ressalto que a palavra "lepra" constitui uma categoria nativa na atual Vila Santo Antônio do Prata (Lopes \& Beltrão, 2017), e, por isso, irei utilizá-la com maior frequência, ao invés do seu sinônimo "hanseníase".

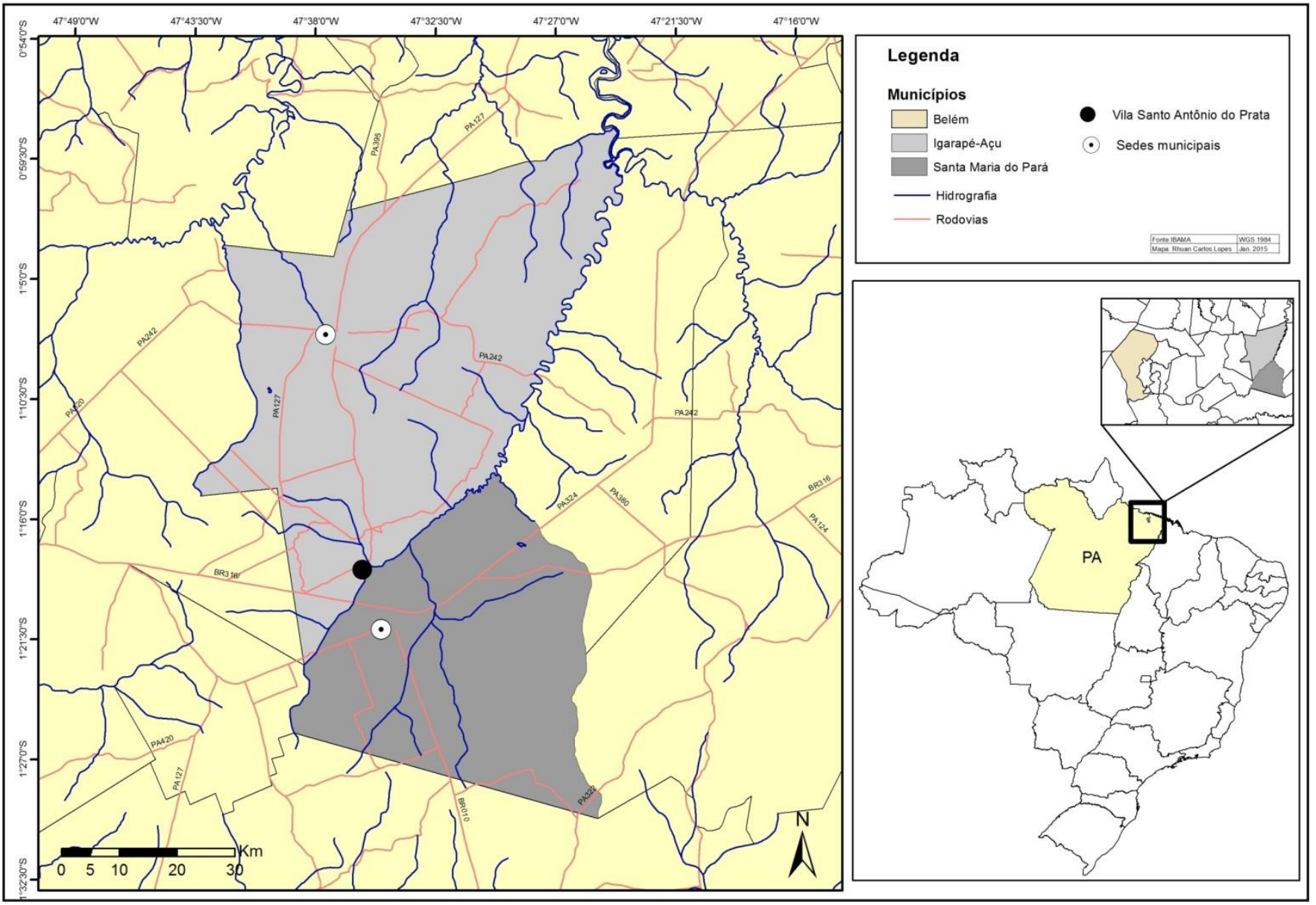

Figura 1: Localização da Vila Santo Antônio do Prata, Pará (Fonte: Produzido pelo autor).

\section{Saúde Pública e a LePRA No BRASIl RePUbLICANO}

O início do século XX coincidiu com a inflexão das políticas de Estado para atenção à lepra, a partir de então entendida como problema de saúde pública nos imperativos republicanos de construção de nação (Cabral, 2013; Leandro, 2013; Ducatti, 2007). Na década de 1910, o movimento sanitarista brasileiro fez o Estado inserir em suas políticas o combate à hanseníase, resultando na criação da Inspetoria de Profilaxia da Lepra e das Doenças Venéreas (IPLDV), em 1920, e culminando com o centralizador Plano Nacional de Combate à Lepra, em 1935 (Barreto et al., 2013). Associadas a isso, entidades filantrópicas se alinharam ao governo de Getúlio Vargas a partir de 1934, na execução de um modelo de saúde direcionado à construção da nação (Leandro, 2013). Assim, entre 1931 e 1945, o governo do presidente Vargas tornou corrente a prática do isolamento em todo território nacional (Cabral, 2013; Monteiro, 2003). Ao conjunto de medidas, inclui-se o estabelecimento de locais de internamento compulsório, os leprosários, apesar da prática do isolamento terapêutico ser combatida pelas agências internacionais desde 1920 (Monteiro, 1998). 
Se até o fim do século XIX a lepra, ou os leprosos, não foram alvo das medidas sistemáticas de nenhum regime de governo, foi com a consolidação da república que ela emergiu enquanto "problema social, uma questão de saúde pública que requeria, pela amplitude e impactos que lhes eram atribuídos, tomadas de posição oficiais" (Câmara, 2009:40). A partir de então, a atuação médica foi preponderante, associada ao discurso de modernidade necessário à evolução da República, em um contexto de ampliação da ação reguladora do Estado no âmbito da saúde (Cabral, 2013; Hochman, 1993).

A doença era compreendida como ameaça sanitária, sem possibilidade efetiva de cura , e o dispositivo da exclusão foi ressignificado nas práticas médicas, sob os argumentos de salvaguarda dos sujeitos sadios (Câmara, 2009). Desse modo, está associado às medidas de controle da lepra o movimento sanitarista, que evocou para si a responsabilidade de ser um dos pilares da construção da nacionalidade brasileira (Cabral, 2013; Hochman, 1993). Nascido na República Velha, esse movimento foi decisivo na continuidade das medidas de saúde pública voltadas à hanseníase no período varguista, quando os leprosários tiveram seu ápice (Cabral, 2013). A medicina, nesse sentido, atuou como o apoio científico para o exercício do poder do Estado brasileiro (Machado et al., 1978).

Os leprosários, então, eram constituídos como colônias. Afastados dos centros urbanos, deveriam possuir infraestrutura que garantisse o seu funcionamento autônomo em relação ao entorno, com o argumento de assegurar atendimento às necessidades dos internos (Barreto et al., 2013). Associados a eles, preventórios e dispensários compuseram o tripé da política de assistência à lepra, a partir da década de 1930 (Monteiro, 1998). Nos primeiros, eram recolhidas as crianças filhas dos doentes, nascidas nas colônias ou separadas dos pais no ato da internação. Já os dispensários eram responsáveis pelo acompanhamento dos chamados "comunicantes", pessoas que haviam tido contato direto com os hansenianos antes do diagnóstico e notificação (Leandro, 2013).

Ducatti (2007) ressalta que tais medidas foram executadas na contramão de ações em outros países, nos quais, desde o século XIX, a reclusão fora substituída gradativamente, por investimentos em saneamento básico e saúde coletiva e práticas educacionais. No entanto no Brasil, o contexto histórico não ensejava tais medidas, posto que

o processo de acumulação capitalista no Brasil não era suficiente para uma empreitada de tal vulto e os movimentos democráticos e sociais não haviam atingido condições políticas que pudessem exigir e pressionar por melhoras substanciais (Ducatti, 2007:304).

Além disso, Ducatti (2007) argumenta que os discursos científico-ideológicos da primeira metade do século XX, em particular nos governos de Getúlio Vargas, foram ensejados por uma elite técnica, em grande medida composta por médicos. Deste modo, as políticas sanitaristas estavam imbuídas de um viés eugênico, no qual o isolamento não tinha por princípio curar os doentes, mas sim proteger os sujeitos sadios (Cabral, 2013; Ducatti, 2007). Com isso, pretendia-se "não macular a classe trabalhadora ainda saudável, passível de disciplina pelo capital" (Ducatti, 2007:308). De fato, o isolamento compulsório estava pouco associado a outro tipo de medida profilática, tais como investimento em saneamento básico ou algum melhoramento em condições nutricionais, de trabalho e habitação nos locais com foco da doença (Monteiro, 2003).

A prática da reclusão de pessoas portadores do bacilo da hanseníase foi oficialmente extinta no Brasil em 1962. Todavia, até a década de 1980 ainda restavam os últimos leprosários em funcionamento no país. As 
mudanças na forma de atenção, por parte do Estado, aos doentes ocorreram também em função da criação de quimioterápicos capazes tanto de propiciar a cura, quanto evitar o contágio nos seus estágios iniciais (Cabral, 2013). Por outro lado, incorporou-se o argumento de que o isolamento fez cair efetivamente as taxas de contágio (Câmara, 2009). De todo modo, é de se salientar que a prevalência dos leprosários por mais de 40 anos enquanto política de Estado teve como foco não a atenção ao tratamento da enfermidade, mas sim a ação de controle sobre os corpos leprosos (Cabral, 2013; Câmara, 2009).

O cerne da exclusão deixou de ter objetivos espirituais, como deixa claro Foucault (1978) para o caso dos lazaretos da Idade Média europeia, apesar do modelo ter ressonância a este período. O padrão de exclusão da lepra fora substituído pelo do controle da peste, também na Europa, com vistas a disciplinar a cidade e agir individualmente sobre os corpos dos afligidos pela doença (Foucault, 1977). Nas sociedades contemporâneas ocidentais esses dois modelos foram conjugados, tendo assim seus elementos basilares unidos: a segregação, advinda da lepra, e a disciplina, oriunda da peste.

Tratar os 'leprosos' como 'pestilentos', projetar recortes finos da disciplina sobre o espaço confuso de internamento, trabalhá-lo com os métodos de repartição analítica do poder, individualizar os excluídos, mas utilizar processos de individualização para marcar exclusões - isto é o que foi regularmente realizado pelo poder disciplinar desde o começo do século XIX (Foucault, 1977:176).

A partir de então, como afirma Foucault (1977), vê-se um tipo de investimento político no corpo que, no caso aqui estudado, tem seu expoente maior na segregação dos doentes hansenianos nos leprosários republicanos. O exercício do poder, como nas demais instituições de controle modernas, é travestido na disciplina, articuladora do controle sobre os corpos que deveriam estar submissos à intenção de ordem (Foucault, 1977). Disciplinando a organização do espaço e do tempo nessas instituições, permitiu-se a vigilância constante do cotidiano, o que está manifesto na arquitetura de prisões, escolas, hospitais e fábricas (Foucault, 1977). Nestes espaços, o exercício da exclusão tornou-se cotidiano, através de medidas que garantissem a efetiva reclusão do doente (Câmara, 2009; Almeida, 2007; Monteiro, 1998, 2003).

Os asilos-colônia, então, podem ser entendidos como instituições totais, do modo como é conceituado por Goffman (1974): em sua tendência ao fechamento, conjugação de residência e trabalho dos leprosos, definido pelo controle de espaço e cotidiano. As instituições desse tipo possuem atributos gerais, mas nem sempre compartilham de todos eles: aspectos cotidianos da vida das pessoas, como dormir, brincar e trabalhar, são reunidos em um só lugar e sob a figura de uma autoridade; as atividades diárias são feitas em conjunto; do mesmo modo, elas são regidas por horários fixos; por fim, tais atividades obrigatórias são racionalizadas de maneira a atender o objetivo da instituição. Entretanto, como indica Câmara (2009), devese ressaltar que o poder exercido nessas instituições não está localizado, necessariamente, nelas mesmas. Para essa autora, a perspectiva de Goffman (1974) não atenta a isso, o que a diferencia de Foucault (1979).

As pesquisas em arqueologia têm demonstrado que é necessário atentar para o conceito de instituição total, proposto por Goffman, considerando que o cotidiano nos leprosários indica a pluralidade nas relações de poder possíveis (Lopes, 2017; Flexner, 2012; French, 1995). Neste trabalho, utilizarei o conceito no sentido de problematizar as pretensões de controle sobre os doentes, tendo em vista as características da Colônia Santo Antônio do Prata. Por outro lado, mostrarei também que as relações de poder propiciavam tensões entre o controle institucional e as "infrações" dos internos (Foucault, 1979). 


\section{A COLÔNIA SANTO ANTÔNIO Do PRATA}

Monteiro (2003) classifica o discurso e a prática do isolamento compulsório de leprosos no Brasil em cinco períodos, cada um com características particulares: de 1900 a 1920 surgiram as primeiras medidas de profilaxia; entre 1921 e 1930 começou o debate sobre o internamento compulsório, a partir da criação do Departamento Nacional de Saúde Pública (DNSP); no terceiro período, entre os anos de 1931 e 1945, o governo Getúlio Vargas sistematizou a criação de colônias de leprosos, ao passo em que o tratamento com sulfona foi descoberto; entre 1946 e 1967, congressos internacionais de medicina condenaram em definitivo o isolamento, culminando com a abolição da prática no Brasil, em 1962; por fim, a partir de 1967, instituiuse o tratamento ambulatorial.

De fato, a cronologia apontada por Monteiro encerra as linhas gerais das políticas para combate à lepra no Brasil, com variações que acompanham as mudanças na organização do Estado brasileiro. Todavia, como aponta a mesma autora, ocorreram exceções, como é o caso de São Paulo: o modelo de exclusão que previa a internação em qualquer estágio da hanseníase foi implementado primeiro neste estado, e foi nele que tais medidas mais tardaram a serem encerradas, em 1967 (Monteiro, 2003).

Ao que parece, o Pará também apresentou particularidades. As negociações do governo estadual com a União, com finalidade de criação do Serviço de Profilaxia Rural (SPR/PA), iniciaram ainda em 1920, com firmamento de acordo em 1921 (Almeida, 2007). Assim, a primeira colônia de leprosos do período republicano foi a de Santo Antônio do Prata, oficialmente inaugurada em 1924, mas em atividade desde 1922 (Souza Araujo, 1924), quando o debate para o isolamento compulsório estava em andamento. Além disso, efetivamente, a colônia teve suas atividades de internação encerradas na década de 1980, com 59 anos de funcionamento.

No Pará a primeira instituição de segregação de leprosos foi o Asilo do Tucunduba. Criado em 1815, no subúrbio de Belém, e sob a administração da Santa Casa de Misericórdia do Pará, este leprosário recebeu os doentes de todo estado. Efetivamente, a maior parte dos internos eram pessoas de poucas posses, já que os abastados atingidos pela doença eram comumente mantidos em suas próprias casas (Henrique, 2012). As condições ditas insalubres desse Asilo foram preponderantes para seu extermínio na década de 1930, quando se argumentava pela adoção de medidas "modernas" coordenadas pela medicina de então (Souza Araujo, 1924).

A entrada do Pará no contexto das ações de profilaxia contou com atuação do leprologista Heráclides de Souza Araújo, primeiro chefe do SPR/PA. Segundo esse médico, o estado contava com elevado número de doentes, verificável pelos números registrados no SPR: para o ano de 1921, havia 1.359 casos, enquanto em 1923, eram 2.052 doentes inscritos (Souza Araujo, 1924). Evidentemente, no quadro de ações do Estado brasileiro, a utilização de tais dados numéricos tinha a função de legitimação da política de combate à lepra, transformada gradativamente em problema de saúde pública através dos discursos médicos e governamentais (Câmara, 2009).

Souza Araújo após percorrer outros lugares no entorno de Belém, com vistas a observar as características elementares para instalação do leprosário modelo, escolheu o Prata como local ideal para a instituição. Naquele momento, no Prata estava em funcionamento a Colônia Correcional Agrícola, que desde 1921 abrigava detentos oriundos da capital do estado. A origem do lugar, porém, é mais antiga: desde 1898 funcionou como Núcleo Colonial Indígena, dirigido pelos padres Capuchinhos. Boa parte da estrutura física 
do Prata fora construída nesse contexto, com vistas a "civilizar" os indígenas Tembé que viviam às proximidades da bacia do rio Maracanã e seus tributários, dentre os quais o rio Prata (Fernandes, 2015; Lopes, 2015, 2016; Beltrão \& Lopes, 2014; Muniz, 1913).

\section{ORGANIZAÇÃO DO ESPaÇO E CONTROLE}

As narrativas de alguns dos ex-internos da Colônia Santo Antônio do Prata repetem frequentemente a dimensão do isolamento, referente aos sadios, e ao controle, relativo ao cotidiano dentro da instituição (Lopes \& Beltrão, 2017). A localização e organização espacial da Colônia de hansenianos foram geridas no sentido de garantir essas duas dimensões da política de combate à lepra no Brasil.

As atividades do leprosário foram iniciadas nas edificações existentes desde o início do século XX. No entanto, aparentemente, apenas dois pavilhões e a igreja foram incorporados em definitivo à estrutura arquitetônica da instituição. O seu projeto de instalação previa a construção de outros edifícios, que visavam o funcionamento efetivo das atividades diárias, seja dos funcionários, seja dos internos. Alguns deles foram de fato construídos durante o funcionamento da Colônia (Souza Araujo, 1948). Nas pesquisas arqueológicas e históricas, efetuadas até o momento, foram localizadas 29 edificações/estruturas, em arruinamento ou em uso pelos atuais moradores da Vila Santo Antônio do Prata (Lopes \& Schaan, 2016). A distribuição dessas estruturas corre em um raio de aproximadamente $2 \mathrm{~km}$. a partir do seu centro urbano. Ao lado disso, verifica-se que a concentração dos prédios históricos diminui nas áreas marginais ao núcleo da Vila (Figura 2).
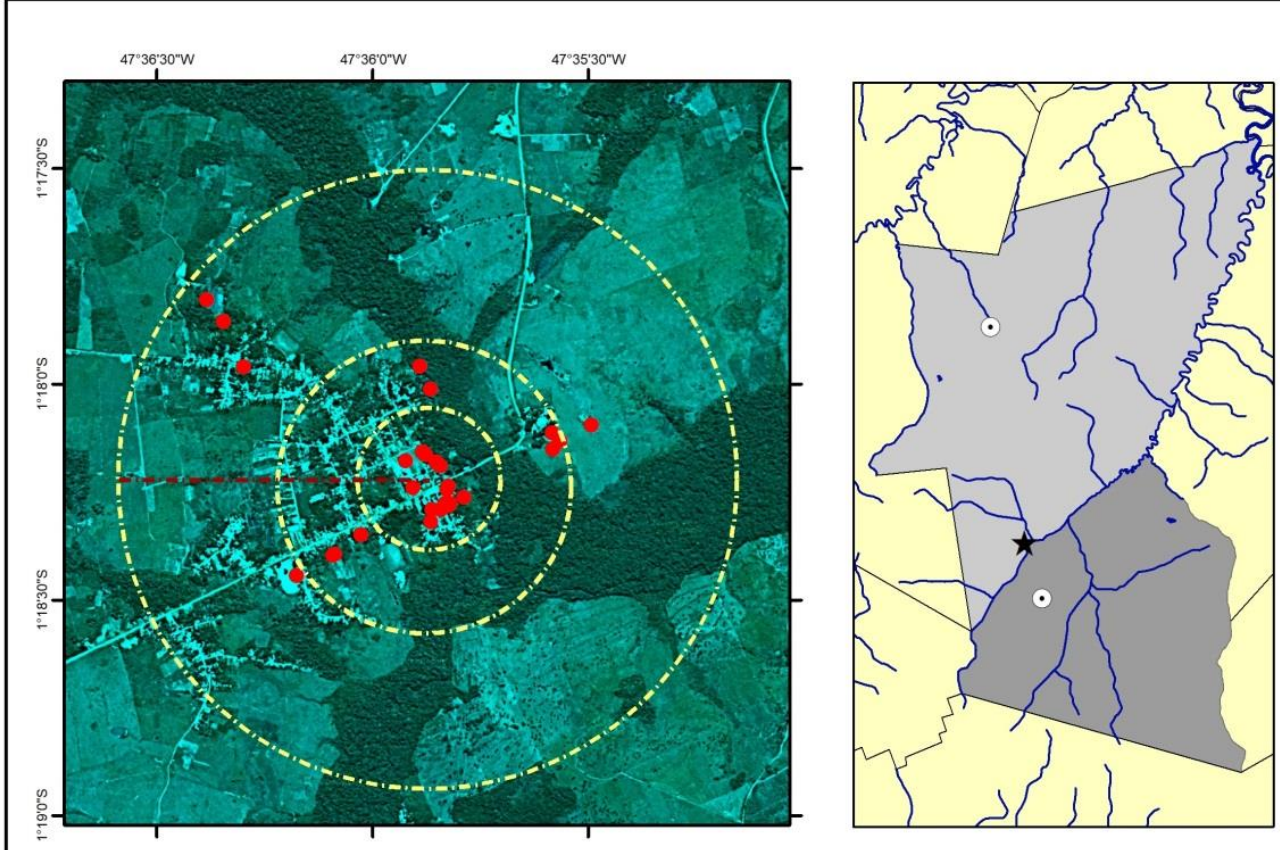

Área do Sítio Arqueológico Santo Antônio do Prata

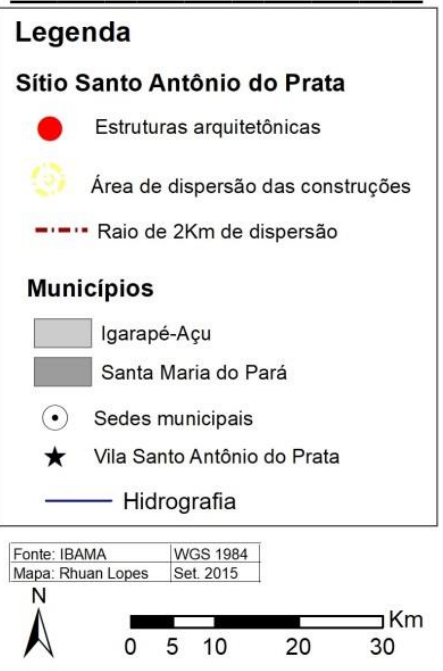

Figura 2: Distribuição de estruturas arquitetônicas na atual Vila Santo Antônio do Prata (Fonte: Produzido pelo autor).

$\mathrm{Na}$ área central da Vila, a topografia é plana, justamente no local onde está instalada a maioria dos prédios já citados. Na zona mais marginal, na qual havia uma estrada de ferro, estação do trem e um forno crematório, ocorre desnível maior no terreno, em direção ao rio Prata (Lopes \& Schaan, 2015). Apesar da 
identificação dessas estruturas, ainda não foi possível verificar a funcionalidade de parte delas; e, ao longo da pesquisa histórica, não foram localizadas todas as suas plantas baixas. Contudo, deduzo que o raio de distribuição das estruturas verificadas no levantamento arqueológico indica o alcance de controle direto exercido na instituição disciplinar.

De fato, os locais de habitação dos internos (pavilhões), hospitais, posto policial, oficinas e cozinha estavam localizados no entorno da praça central da Colônia do Prata; as casas de familiares, porém, foram erguidas nas ruas adjacentes. Toda essa área era denominada de "perímetro de isolamento", na qual doentes eram mantidos sob controle da administração. Já os prédios administrativos e casas dos funcionários ficavam fora dessa zona (Souza Araujo, 1948, 1924). Quando o leprosário foi inaugurado em 1924, possuía 23 quarteirões, subdivididos em 16 lotes urbanos (Souza Araujo, 1924). As principais construções eram oriundas do Núcleo Colonial Indígena, erguidas nas duas décadas iniciais do século XX: a igreja em estilo renascentista, os dois pavilhões nos quais funcionaram os educandários das crianças indígenas, além das 76 habitações, classificadas em sua maior parte como "barracas" (Souza Araujo, 1924:54).

Essa classificação efetuada pelo criador do leprosário indica, provavelmente, a arquitetura vernácula característica dos núcleos coloniais amazônicos do início do século XX, compostos por casas de pau-a-pique (Lacerda, 2010). Esse tipo de construção não estava inserido nas expectativas arquitetônicas referentes às colônias de hansenianos, considerando que a perspectiva de higiene pressupunha, também, ambientes conceituados como arejados e salubres (Souza Araujo, 1948, 1924). Apesar disso, a estrutura do antigo Núcleo Colonial Indígena estava dentro dos pressupostos mínimos das normas médico-sanitárias do começo do século: a relativa distância dos centros urbanos; acesso por via ferroviária; terrenos no entorno, que serviriam tanto para efetivar o isolamento contra possíveis contaminações aos moradores vizinhos, quanto para o cultivo agrícola; além dos pavilhões construídos nos anos da administração dos padres Capuchos (Souza Araujo, 1924).

O memorial produzido por Souza Araujo (1924) fornece as indicações das prováveis construções a serem executadas no leprosário, inclusive com demonstração de sua distribuição no conjunto urbano da Colônia. A futura conjugação desse tipo de informações históricas com os dados arqueológicos, analisados a partir da Teoria da Sintaxe Espacial (Hillier \& Hanson, 1984), permitirá o entendimento da organização espacial do leprosário, tendo em vista a análise da relação entre os espaços físicos.

No entanto, a aplicação de modelos de análise morfológico-espacial de estruturas arquitetônicas nas plantas baixas disponíveis (Zarankin, 2005; Hillier \& Hanson, 1984) permitiu a discussão acerca de uma das dimensões de controle atuantes no leprosário, como demonstrarei nas seções seguintes.

\section{ARQuiteTURA E CONTROLE DE CORPOS}

Conceitualmente, a arqueologia da arquitetura - tal como é denominada, apesar de não constituir um campo novo - é entendida como o estudo da arquitetura pela perspectiva da arqueologia (Steadman, 1996). Trata-se de pensar as edificações como "superartefatos" (Najjar, 2011; Leone \& Potter Jr., 1988) passíveis de serem pensados a partir dos debates sobre cultura material, mas com atenção às suas especificidades. Zarankin (2008: 326) argumenta que as edificações são objetos sociais, "carregados de valores e sentidos particulares" e, por isso, imbuídos de ideologia, o que os torna capazes de construir pessoas. Assim, os edifícios são pensados em sua complexidade: componentes ativos do meio social, estruturadores da cultura e 
por ela estruturados (Kamp, 1993), conformadores, então, da paisagem (Zarankin \& Niro, 2010; Zarankin, 2005).

A arquitetura remanescente, então, é tida como um dos elementos da paisagem moderna, carregada de significados que podem ser lidos de múltiplas maneiras. Desse modo, os prédios aqui tratados são investigados tendo em vista suas características construtivas, a organização interna, bem como a sua disposição espacial. Para analisar a configuração desses espaços, utilizo dois modelos de análise morfológicoespacial. O modelo Gamma consiste na representação gráfica da compartimentação de dado edifício, sendo possível a verificação dos níveis de integração dos cômodos, da complexidade de sua organização e da circulação entre os mesmos (Hillier \& Hanson, 1984). A partir disso, as edificações podem ser classificadas como distributivas ou não distributivas, quando os cômodos possuem mais de uma via de acesso ou apenas uma. Associado a esse modelo, utilizo também os índices de escala, integração e complexidade propostos por Blanton (1994), que auxiliam na interpretação nos gráficos do modelo Gamma, além de maximizar e tornar possível a comparação das informações geradas em diferentes plantas-baixas (Zarankin, 2005, 1999). O método proposto por Blanton possibilita a comparação diacrônica de estruturas diferentes.

Sendo assim, as plantas baixas de dois pavilhões, construídos em momentos distintos, foram decompostas em gráficos. Neles, cômodos são representados por nodos, enquanto que seus acessos são traduzidos em linhas (Blanton, 1994; Hillier \& Hanson, 1984; Hillier et al., 1987). Esse gráfico, então, representa a configuração espacial do edifício, permitindo a visualização dos percursos possíveis no seu interior (Hillier \& Hanson, 1984). A partir dele, é possível efetuar cálculos que indicam os índices propostos por Blanton (1994). O índice de escala corresponde ao número de nodos verificáveis na planta baixa; o índice integração diz respeito às possibilidades de circulação dentro do prédio, sendo que o valor mínimo deste índice é 1, já que cada cômodo (nodo) precisa de ao menos uma entrada/saída; os índices de complexidade A e B referem-se à quantidade de conexões entre os nodos e à acessibilidade dos nodos com o exterior do prédio, respectivamente.

\section{Os PAVILHÕES DE INTERNAMENTO: ANÁLISE MORFOLÓGICO-ESPACIAL}

Ao chegarem ao Leprosário do Prata, os doentes de hanseníase eram instalados nos pavilhões de internamento. Doentes sozinhos, solteiros ou casados, bem como as crianças, eram instalados nos pavilhões, nos quais conviviam com dezenas de outros internos. Nos prédios herdados do Núcleo Indígena, havia a expectativa de abrigar 2000 doentes, divididos de acordo com faixa-etária, gênero e estado civil (Souza Araujo, 1924). Posteriormente, em 1935, três "modernos pavilhões", com 21 leitos cada, além de 21 casas para famílias, foram inaugurados no Prata (Souza Araujo, 1948:144), o que demonstra o aumento da demanda por mais acomodações para a crescente população de portadores da doença. A essa época, já consta a existência de "cozinha a vapor" para produção de alimentos aos internos, o prédio da administração, posto policial, escola e cassino (Souza Araujo, 1948).

Todos os internos recebiam um número de matrícula, pelo qual eram conhecidos dentro da instituição. Com horários regulados, os doentes desenvolviam atividades produtivas, de recreação e de atenção à saúde nos diferentes e específicos espaços da Colônia. Contudo, segundo o regimento interno, os moradores deveriam se recolher aos pavilhões ou casas a partir das 18 horas; a polícia local, então, deveria trancar tais 
prédios e executar rondas na Vila, a fim de auxiliar o administrador na garantia "da ordem e disciplina no estabelecimento" (Souza Araujo, 1924:61).

Tendo em vista o elevado número de pessoas internadas nos pavilhões, bem como a posição destes prédios na organização espacial da Colônia, recaíram sobre eles as análises que proponho neste artigo. Dentre as edificações anteriores a 1924, tive acesso apenas à planta do pavilhão que originalmente foi construído como educandário feminino na época do Núcleo Indígena (1898-1920) (Figuras 3 e 4). Voltado para o Largo de Santo Antônio, o Pavilhão fica ao lado da Igreja principal do Prata, na primeira rua do quarteirão seis. Sua fachada principal possui características da arquitetura clássica: as quatro pilastras estruturais são apoiadas em pedestais, visíveis apenas na parede do pavimento superior; o entablamento é composto por cornija, sob as quais há dentículos, e capitel adornado com volutas. Sobre esse conjunto, há platibanda encimada por um frontão em arco. Este último elemento se repete sobre a porta centralizada, sendo que as quatro janelas possuem frontões triangulares. Uma escadaria em forma de lira dá acesso à entrada principal, e sob ela há uma porta pela qual é possível entrar diretamente no pavimento inferior (Souza Araujo, 1924) (Figura 3). Na porção inferior da fachada, ocorre decoração em rusticato, que emolduram as aberturas e dão um tom robusto à composição (Serique, 2015; Ching, 2010).

Em tempos de leprosário, o prédio recebeu a denominação de "Pavilhão D", “constituído por corpo único" (Muniz, 1913:14), com um pavimento superior e "porão habitável”, com 10 amplas salas e banheiros, com espaço suficiente para 200 internos adultos, solteiros e viúvos. No pavimento térreo havia duas celas, "reservadas para doentes detentos, loucos e indisciplinados" (Souza Araujo, 1924:118), provavelmente adaptadas durante o uso do espaço como Centro de Correção, em 1921. Para o início das atividades do leprosário, o Pavilhão foi reformado e ampliado, com acréscimo de dois cômodos na porção posterior - um em cada pavimento - com entradas independentes acessíveis por escadas.

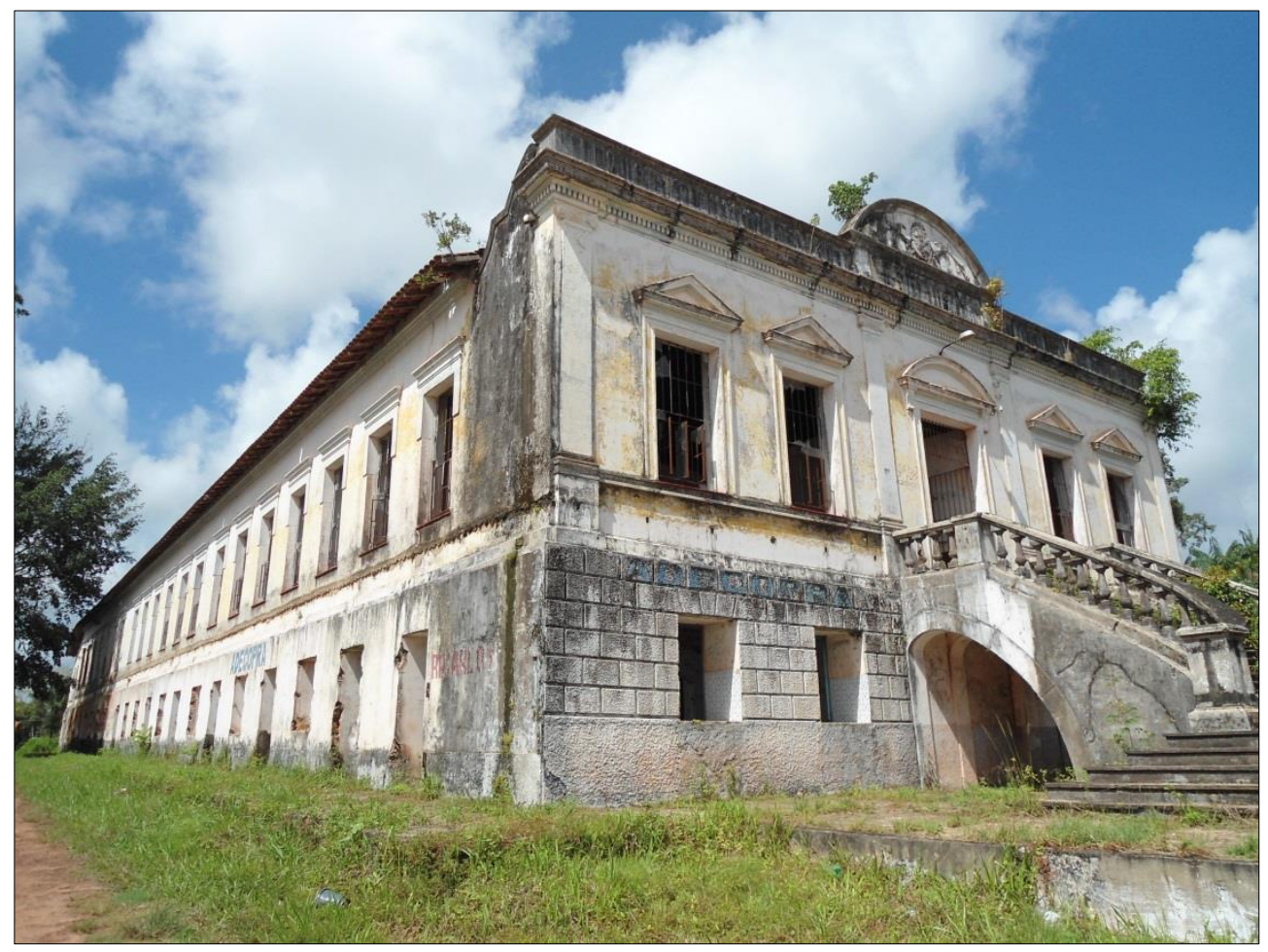

Figura 3: Fachada contemporânea do Pavilhão D, contendo traços originais (Fotografia do autor). 
A aplicação dos modelos de análise morfológico-espacial na planta baixa do Pavilhão D permitiu a observação da organização e distribuição dos espaços do prédio (Figura 4). O índice de escala de 34 demonstra a grande dimensão do Pavilhão, enquanto que o índice de integração de 1,65 indica a possibilidade de circulação baixa. Ao lado disso, o prédio apresenta estrutura não distributiva, ou seja, a circulação pode ser controlada a partir de um ou dois espaços específicos no prédio, havendo pouca integração entre os nodos (Hillier \& Hanson, 1984). Isso é ilustrado no gráfico de conexões, no qual os valores mais altos correspondem a uma ou duas conexões por nodo (Figura 4) (Zarankin, 2005).

Pelo gráfico de análise Gamma é possível verificar que a circulação pelo prédio está condicionada pelos corredores dos pavimentos superior e inferior, aqui considerados também como nodos (respectivamente, $1 \mathrm{e}$ 22) (Figura 5). Assim, apesar do alto índice de complexidade A indicar a existência de muitas conexões entre os nodos, grande parte delas está direcionada para um dos corredores (Tabela 1). Mesmo com três entradas/saídas possíveis, o índice de complexidade B de 2,1 indica o significativo grau de isolamento em relação ao exterior, o que é corroborado pelo gráfico de análise de acessibilidade (Figura 6). Isso significa dizer que é necessário percorrer ao menos 2,1 cômodos para sair do Pavilhão. Por fim, essa configuração caracteriza a organização panóptica do Pavilhão, na qual a perspectiva de vigilância é garantida pela centralidade de um espaço - notadamente os corredores - em relação ao outro (Foucault, 1977). 


\section{Pavilhão D}
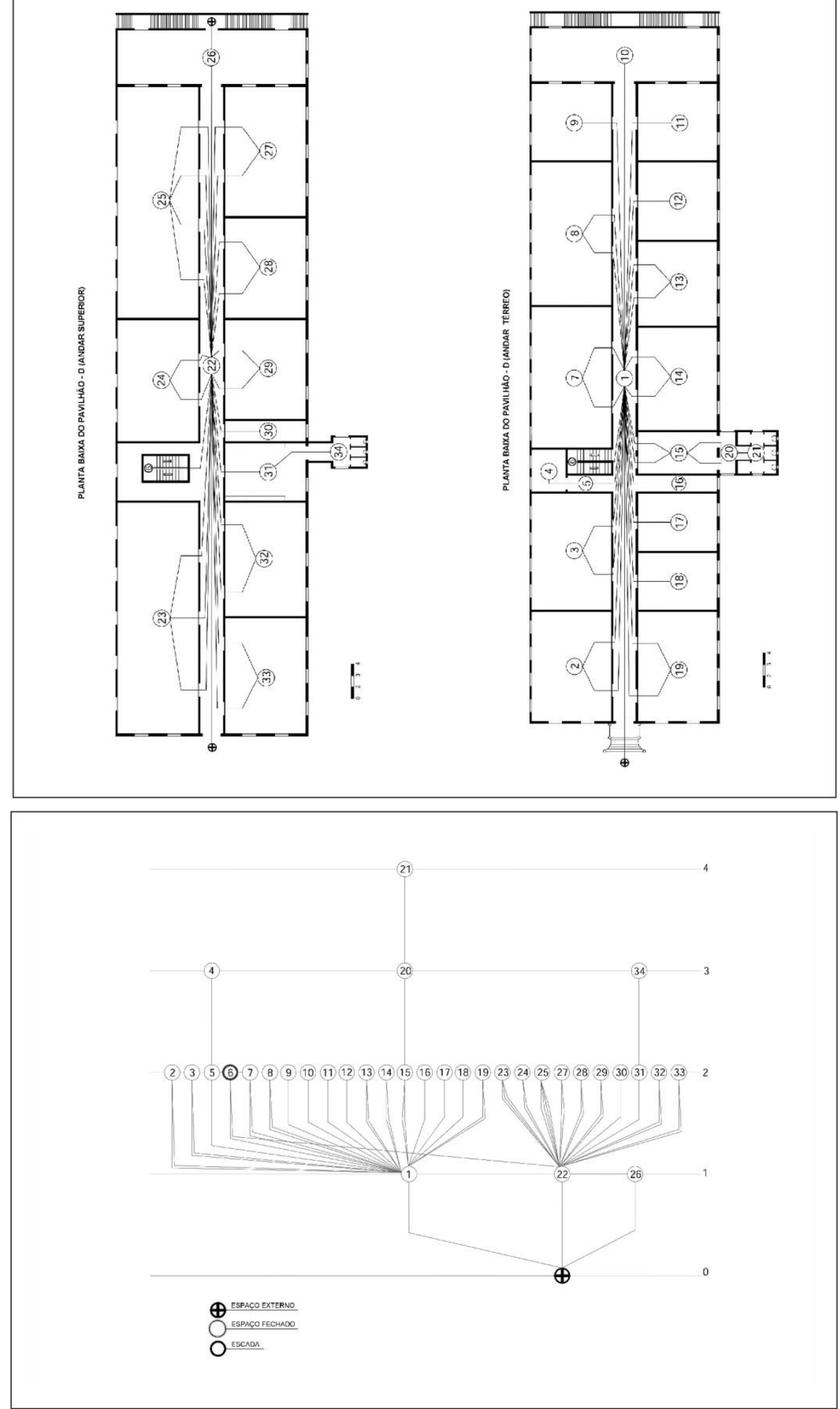

Figura 4: Análise morfológico-espacial do Pavilhão D (Fonte: Adaptado de Souza Araújo, 1924: 54; Desenho dos gráficos: Vivaldi Silva) 
LEPRA, POLÍTICAS SANITÁRIAS E CONTROLE SOCIAL: ISOLAMENTO E COTIDIANO

NA LAZARÓPOLIS SANTO ANTÔNIO DO PRATA, PARÁ

\begin{tabular}{c|c}
\hline Índice de escala & Índice de integração \\
34 & 1,65 \\
\hline Índice de complexidade A & Índice de complexidade B \\
60 & 2,1 \\
\hline
\end{tabular}

Tabela 1: Tabela de índices, Pavilhão D.

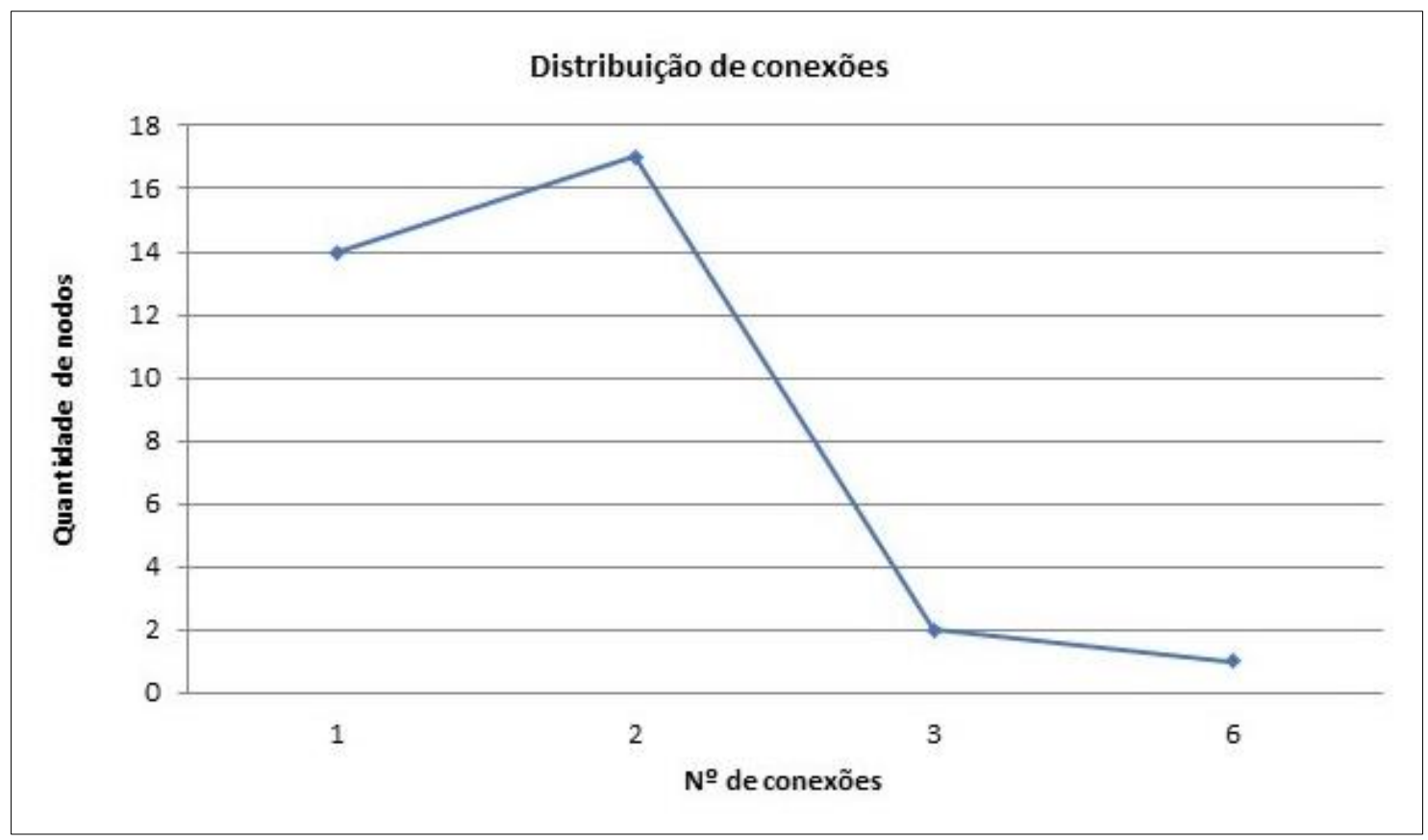

Figura 5: Distribuição de conexões no Pavilhão D

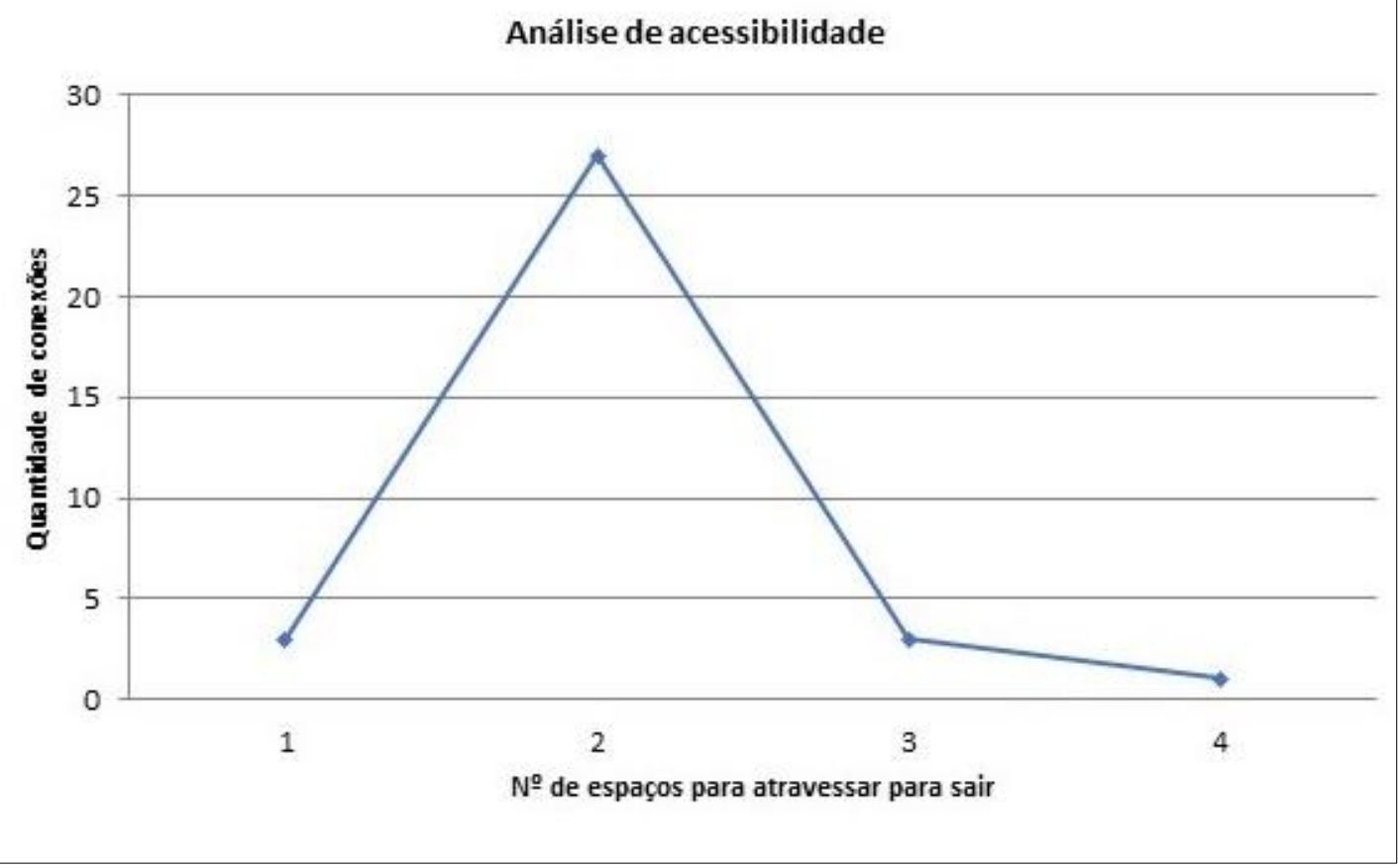

Figura 6: Análise de acessibilidade no Pavilhão D. 
O outro Pavilhão, referido como “moderno" (Souza Araujo, 1948:144), foi inaugurado em 1935 e apresenta configuração inserida nas demandas contemporâneas do leprosário. As dimensões eram menores, e a fachada era austera e simples (Figura 7). Composto por um pavimento, o prédio era ladeado por varandas, contendo duas entradas e 14 janelas na fachada principal. A porta frontal dava acesso à sala de estar, e nas laterais localizavam-se dois dormitórios; os banheiros ficavam na porção posterior, voltados à sala (Figura 8).

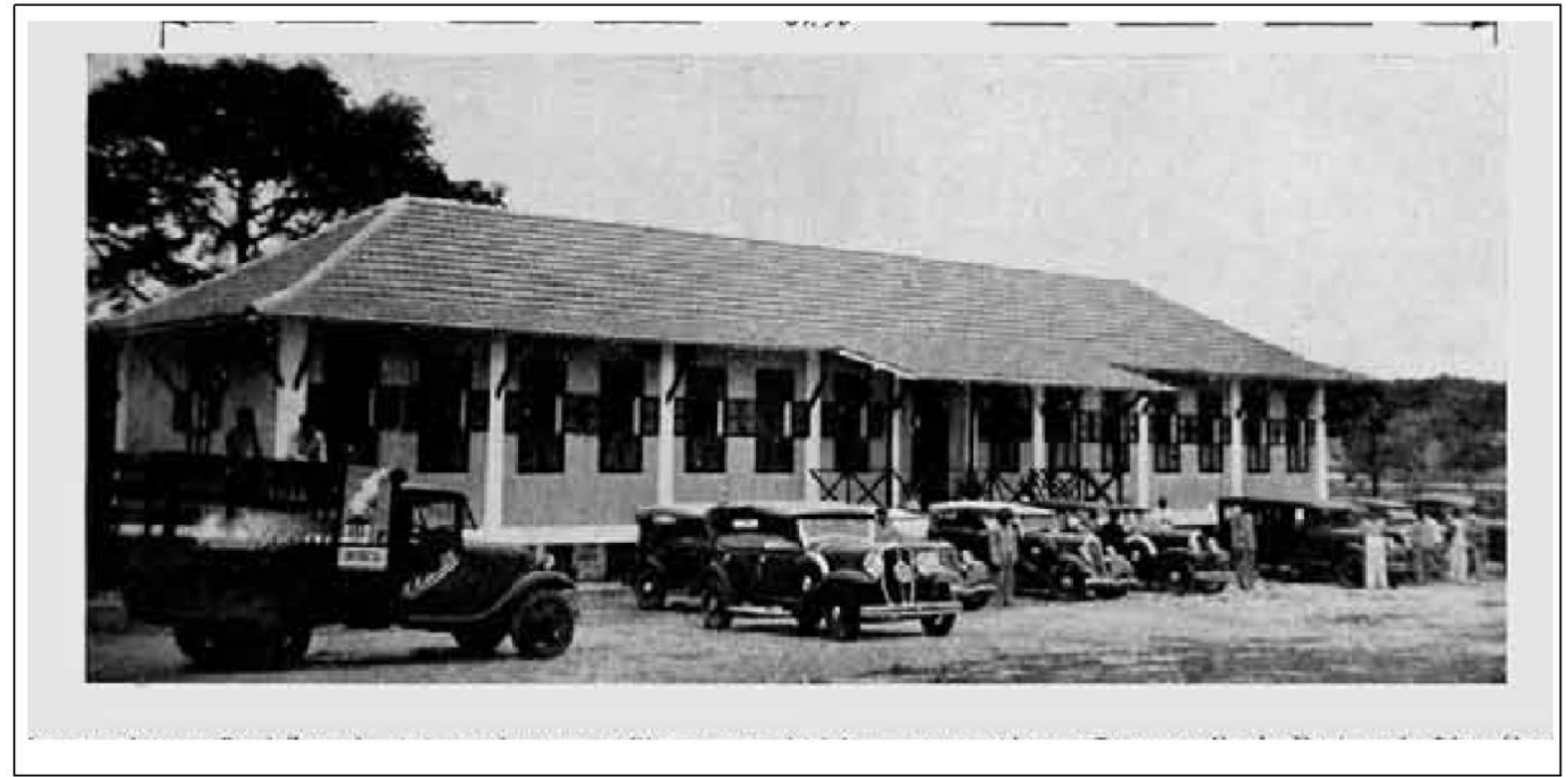

Figura 7: Pavilhão Moderno (Fonte: Souza Araújo, 1948: 103).

O índice de escala de 9 demonstra a pequena dimensão do Pavilhão Moderno, enquanto o índice de integração de 1,11 indica a reduzida possibilidade de circulação, tendo em vista que há apenas um acesso na maior parte dos cômodos (Tabela 2). Assim, o prédio poderia ser classificado como não-distributivo, considerando também que o pico no gráfico de conexões ocorre no menor número de conexões possíveis (Figura 9). Pelo gráfico de análise Gamma é possível verificar que a circulação pelo prédio está condicionada pela sala de estar (nodo 2), responsável pela distribuição aos outros cômodos. Mesmo com duas entradas/saídas possíveis, o índice de complexidade B de 2,1 indica o elevado grau de isolamento em relação ao exterior, o que é corroborado pelo gráfico de análise de acessibilidade em formato piramidal (Figura 10). Desse modo, o Pavilhão Moderno se caracteriza por uma organização panóptica. 


\section{Pavilhão Moderno}
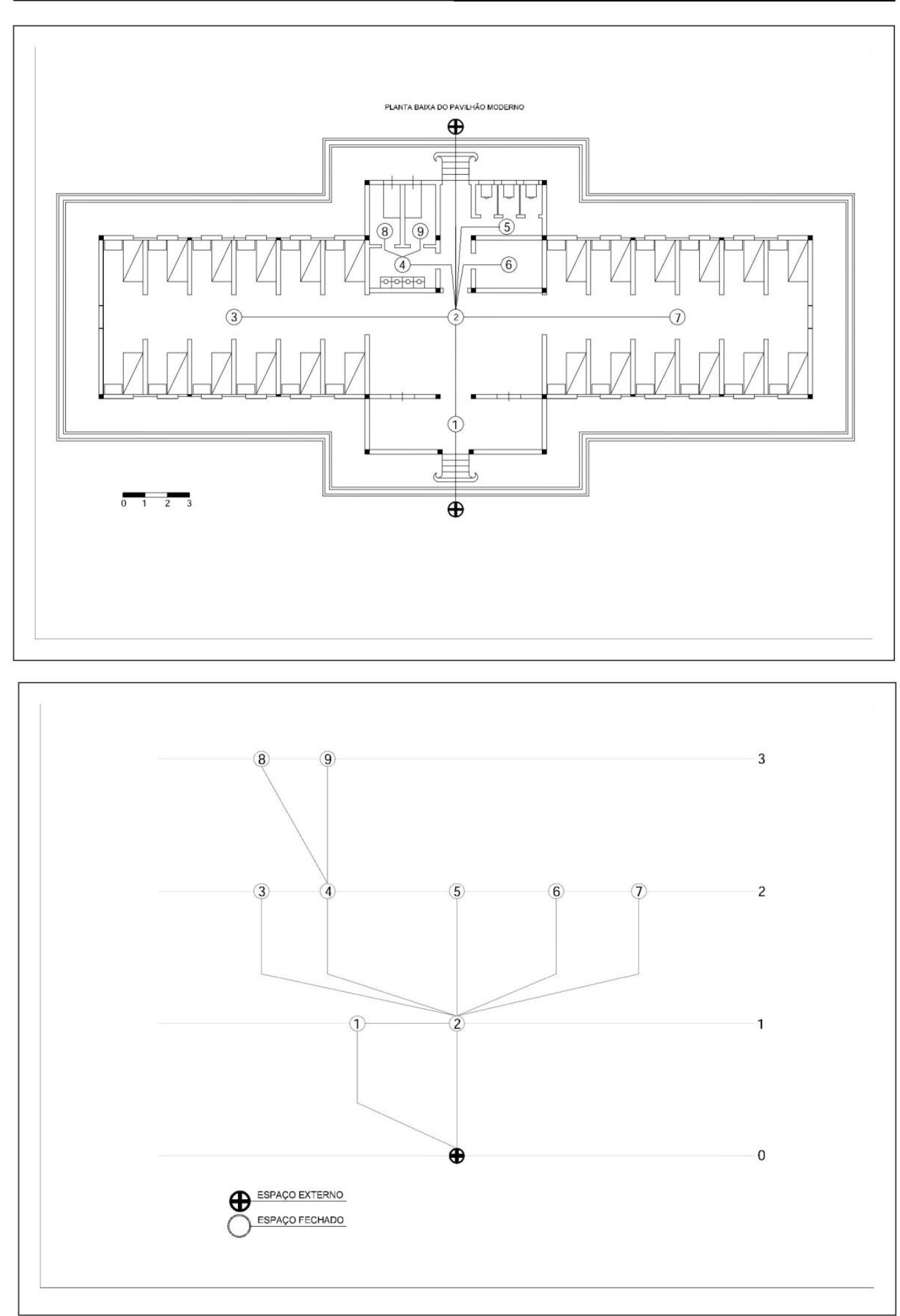

Figura 8: Análise morfológico-espacial do Pavilhão Moderno (Fonte: Adaptado de Souza Araújo (1948: 103; Desenho dos gráficos: Vivaldi Silva). 


\begin{tabular}{c|c}
\hline Índice de escala & Índice de integração \\
9 & 1,11 \\
\hline Índice de complexidade A & Índice de complexidade B \\
18 & 2,1 \\
\hline
\end{tabular}

Tabela 2: Tabela de índices, Pavilhão Moderno.

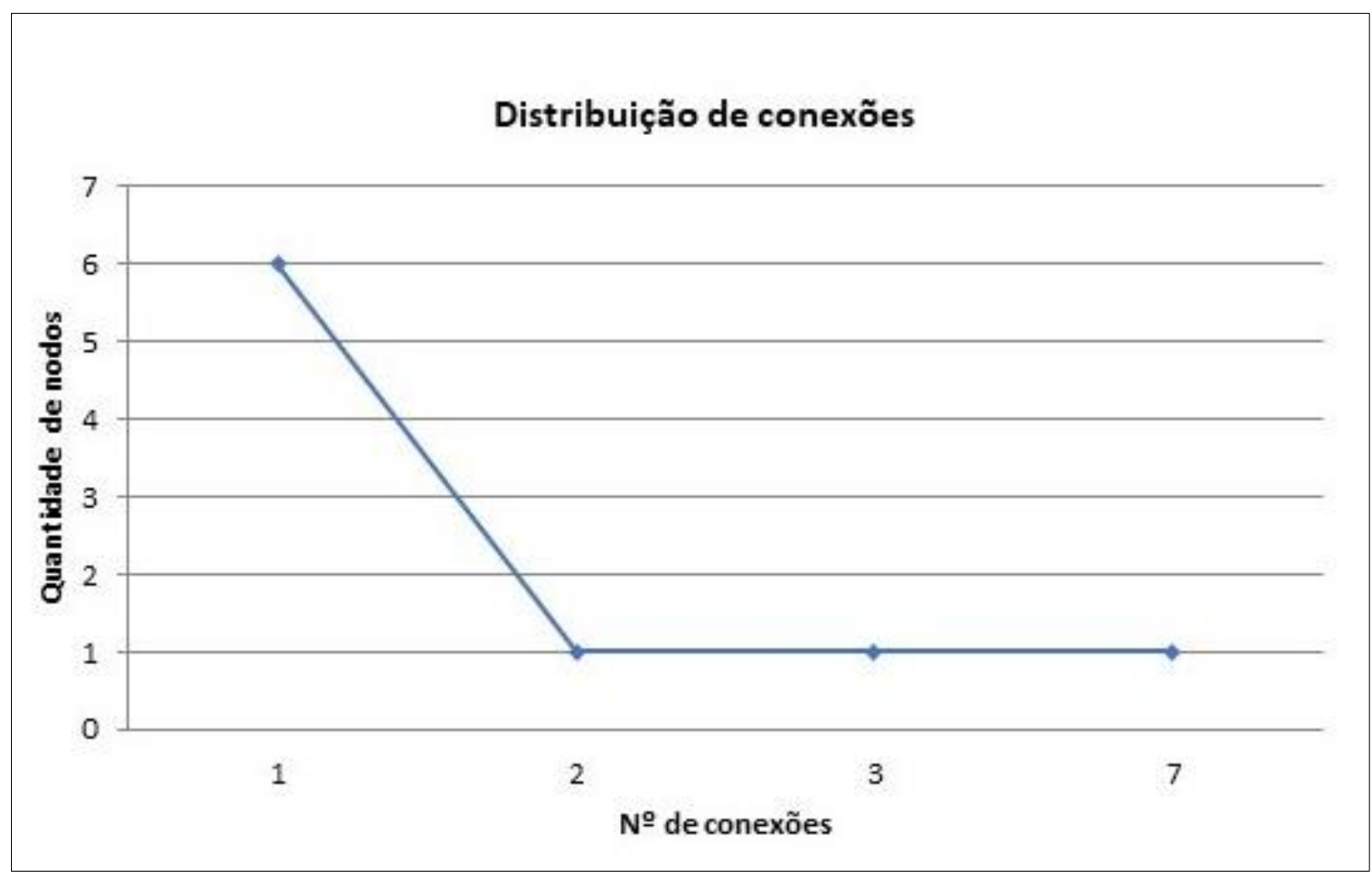

Figura 9: Distribuição de conexões no Pavilhão Moderno.

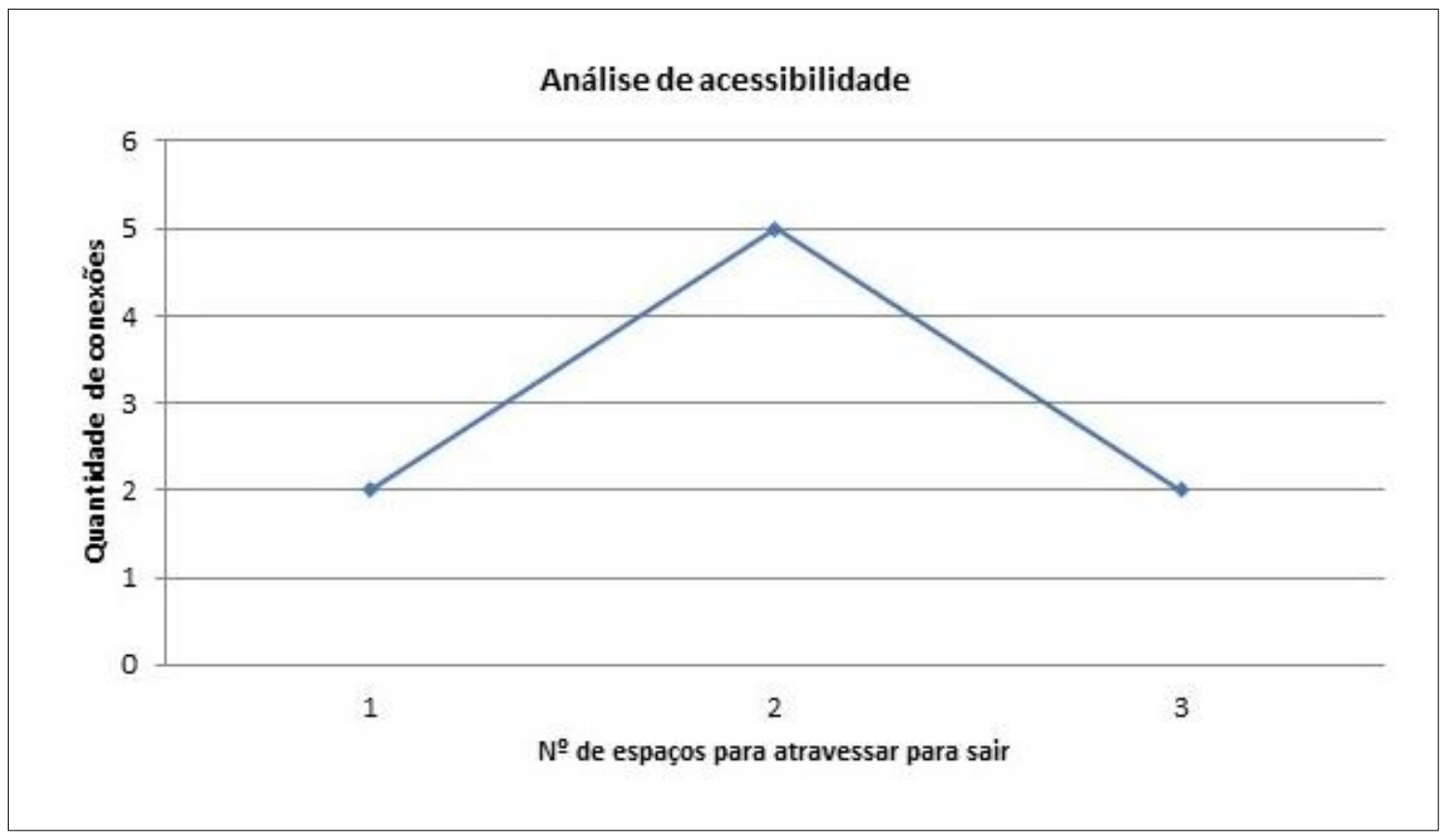

Figura 10: Análise de acessibilidade no Pavilhão Moderno. 
Os dois pavilhões analisados apresentam períodos diferentes de construção, bem como dimensões e estilos arquitetônicos diversos entre si. No entanto a comparação entre os índices de integração demonstra similaridades quanto ao controle de circulação nos prédios (Tabela 3). Em ambos os casos, os limites impostos pela disposição dos cômodos, assim como a quantidade de acesso a cada um deles, indicam a intenção de controle sobre as interações sociais ocorridas nas edificações (Blanton, 1994). Os gráficos Gamma mostram a coincidência da forma panóptica simples nas duas construções: uma célula básica para qual convergem os cômodos do entorno (Zarankin, 2001).

\begin{tabular}{c|c|c|c|c}
\hline Prédio & Índice de escala & Índice de integração & Índice de complexidade A & Índice de complexidade B \\
\hline Pavilhão D & 34 & 1.65 & 60 & 2.1 \\
\hline Pavilhão Moderno & 9 & 1.11 & 18 & 2.1 \\
\hline
\end{tabular}

Tabela 3: Comparação dos índices, Pavilhão D e Pavilhão Moderno.

No Pavilhão D, apesar das reformas e acréscimo de cômodos à época do leprosário, observa-se a manutenção da lógica de controle presente no prédio original, construído com fins educacionais e no bojo da política homogeneizadora do governo paraense (Lopes, 2016; Fernandes, 2015; Beltrão \& Lopes, 2014; Beltrão, 2012). A existência de celas no pavimento inferior reforça esse argumento, na medida em que a arquitetura monumental, associada ao modelo panóptico, atuam como instrumentos de domesticação de corpos, tanto nos ambientes escolares modernos, quanto em prisões (Zarankin \& Niro, 2010; Zarankin, 2005; Foucault, 1977). Não por acaso, esse mesmo pavilhão foi readaptado, na década de 1990, para funcionar como escola de ensino fundamental. Como indiquei em outro trabalho (Lopes, 2016), a ocupação por diferentes instituições totais do mesmo espaço construído indica a continuidade da lógica de controle e exclusão, primeiramente aplicada aos Tembé/Tenetehara, depois a segmentos sociais considerados espúrios, como criminosos e os portadores da hanseníase.

Por outro lado, os índices de integração e de escala do Pavilhão Moderno são significativamente menores em relação ao Pavilhão D, apesar do índice de complexidade B ser o mesmo. Suponho, em função disso, que as construções erguidas durante o período do leprosário tenham aumentado gradativamente o controle sobre a circulação de pessoas na instituição, particularmente nos pavilhões. Ao que parece, uma das maneiras de efetivar essa medida era diminuir o tamanho dos prédios e, consequentemente, a quantidade de pessoas que neles residiam. Apesar da análise aqui efetuada ter recaído em apenas um dos pavilhões inaugurados em 1935, vale lembrar que todos eles foram construídos a partir da mesma planta baixa (Souza Araujo, 1948).

Provavelmente, o controle exercido nos pavilhões possuía alguma particularidade, tendo em vista a quantidade de pessoas em um só lugar, além dos tipos sociais que neles eram internados: solteiros/as, jovens, viúvos/as. As casas familiares construídas no leprosário comportavam, a rigor, poucas pessoas, em geral as famílias que se formavam na Colônia do Prata ${ }^{3}$. De todo modo, como informam os documentos históricos e os etnográficos, esses espaços eram trancados e abertos em horas específicas do dia (Lopes \& Beltrão, 2017; Souza Araujo, 1924,). Além de impedir, ou, ao menos, dificultar, a circulação entre os prédios, tal medida

${ }^{3}$ Casamentos eram possíveis e estimulados entre os internos. 
indica o espraiamento do controle sobre toda a instituição, que provavelmente alcançava o raio de distribuição das construções relativas ao leprosário.

Os modelos de análise morfológico-espacial, assim, confirmam as projeções de controle sobre os corpos dos doentes de hanseníase internados na Colônia do Prata. Considerando que os limites impostos pelas edificações condicionam comportamentos e regulam corpos (Zarankin, 1999), entendo que a organização dos Pavilhões de internamento garantia parte da política de isolamento referente à lepra no Brasil.

Os modelos de interpretação da organização espacial, no entanto, não possibilitam interpretações quanto aos usos diferenciados e ressignificações dos espaços por parte dos usuários (Moreira \& Soares, 2015; Zarankin, 2001). Flexner (2012), por exemplo, ao investigar o leprosário de Kalawao, no Havaí, demonstrou que práticas cotidianas dos internos destoavam das características de uma instituição total. Nesse caso, a partir dos dados arqueológicos, foi possível verificar que as relações sociais estavam também condicionadas pelos códigos culturais locais, baseados na tradição.

Dados etnográficos gerados a partir de entrevistas e observação participante junto aos ex-internos da Colônia do Prata dão um tom mais dinâmico e vivo ao controle almejado via arquitetura. Como demonstrarei na seção seguinte, o cotidiano dos internos era permeado por relações de poder dentro da instituição bem como pela quebra às regras estabelecidas.

\title{
COTIDIANO DOS INTERnOS: “FOI PRO PRATA, JÁ ERA!"
}

\author{
"Quando o Prata adormece \\ Sobre o manto estrelado do céu \\ E quando a neblina desce \\ Envolvendo o arvoredo em finíssimo véu \\ Triste é o silêncio \\ Nenhum pequeno rumor \\ Nem sequer a leve aragem \\ Na paisagem da cidade da dor \\ Mas quando o Prata desperta \\ Sob o clarão da alvorada \\ As palmeiras libertas \\ Das gélidas brumas da madrugada \\ Traduz um esquecido contraste \\ Da alma da cidade \\ Expressando a dor, o riso, o gemido e a saudade." \\ (Hino da Colônia Santo Antônio do Prata) ${ }^{4}$
}

Entre os atuais moradores da Vila Santo Antônio do Prata, a categoria nativa para designar os doentes outrora internados é a de "ex-internos”. Ela tem equivalência também àquele que é leproso ou doente, mesmo que esteja curado atualmente. Ao lado disso, entre os interlocutores desta pesquisa, "lepra" continua sendo a designação utilizada para referir-se à doença, tendo em vista sua profundidade temporal e seu peso enquanto estigma social (Lopes \& Beltrão, 2017).

Alguns desses moradores são costumeiramente indicados como referência sobre a história do lugar, justamente por terem passado boa parte de suas vidas como “internos”. Um deles é Jó ${ }^{5}$, reconhecido na Vila

\footnotetext{
${ }^{4}$ Hino recitado durante entrevista realizada com ex-interno, em outubro de 2013.

${ }^{5}$ Entrevista realizada em maio de 2014, na Vila Santo Antônio do Prata, município de Igarapé-Açu (Pará). Para resguardar as identidades dos interlocutores, seus nomes foram trocados, bem como algumas narrativas foram cruzadas, tendo em vista os estigmas que os afetam
} 
como o morador vivo mais antigo do Prata. Jó conta que chegou à Lazarópolis em oito de junho de 1938. Porém, esse não foi o início de sua experiência como interno. Nascido em Cametá, cidade do baixo rio Tocantins, nordeste do Pará, Jó foi levado pela irmã à Belém em março de 1931. Depois de alguns dias na casa de uma amiga da família, residente na Vila de Icoaraci, Jó foi deixado no Asilo do Tucunduba, no subúrbio da capital paraense. Com apenas 12 anos de idade, ele conheceu um dos leprosários mais antigos do Pará (Henrique, 2012).

Aos 19 anos, porém, ele foi transferido para a Colônia do Prata, logo após a extinção do Asilo do Tucunduba, considerado fora dos padrões de higiene necessários ao isolamento de leprosos (Souza Araujo, 1924). Jó chegou no décimo quinto ano de existência do Leprosário e se estabeleceu no Pavilhão D. Como ele bem lembra, havia quatro pavilhões de uso coletivo, denominados alfabeticamente: os A, B e C eram femininos, enquanto que no D moravam os homens. Atrás deles ficavam os refeitórios.

Segundo Jó, o rigor extremo no controle dos doentes oscilava em função dos diretores e até mesmo do regime de governo vigente no país. Um dos ápices do autoritarismo, segundo o interlocutor, foi no governo estadual de Jarbas Passarinho (1964-1966), durante o início do regime militar brasileiro. Não por acaso, controle é outra categoria recorrente no depoimento dos ex-internos. É possível verificar nos livros de registros da instituição alguns paralelos às narrativas dessas pessoas. O tom da disciplinarização ganha destaque com Miriam ${ }^{6}$, outra ex-interna, quando falou brevemente sobre sua chegada ao Prata.

Miriam foi internada em 1954, um ano depois de seu pai e dois de seus irmãos. Nascida em uma vila no interior do município de Bragança, perdeu o contato com a mãe, única pessoa sadia do núcleo familiar, que, por sua vez, constituiu outra família. A interlocutora fala com serenidade sobre a opção de sua mãe em casarse novamente, uma vez que o internamento no Prata, como em qualquer outro leprosário, recorrentemente implicava em desestruturação familiar e perda dos laços sociais externos à instituição (Barreto et al., 2013; Monteiro, 1998). Para usar as próprias palavras de Miriam: "Foi para o Prata, já era!”.

Miriam chegou ao leprosário aos nove anos de idade. Nessa época, outro asilo destinado aos leprosos do estado estava em funcionamento no Pará, o leprosário de Marituba, em atividade desde 1942 (Silva, 2009). Para lá nossa interlocutora foi transferida, no mesmo ano de 1954, por "ser muito criança", segundo ela mesma. Ao completar 13 anos, ela retornou ao Prata. Todavia, de acordo com prontuário médico da interna - documento no qual eram registradas informações sobre o tratamento e conduta dos doentes durante o internamento (Souza Araujo, 1924) -, Miriam fugiu da Colônia em 1960, regressando no ano seguinte, casando-se em seguida com outro interno (Prata, 1954). A mulher, porém, fala apenas das guaritas de segurança e correntes de ferro que fechavam as duas entradas da Colônia. A saída e ingresso de pessoas, internos ou não, era controlada nesses pontos estratégicos.

Miriam e Jó lembram que rondas eram efetuadas ao longo do dia e um desses guardas também era o responsável por trancar as portas dos pavilhões, às 18 horas, e reabri-las às 6 horas, na manhã seguinte. A partir de então, nenhum doente poderia circular na Colônia, sem a devida autorização. Essas narrativas permitem entender os versos do Hino do Prata citado no início deste tópico. $\mathrm{O}$ encerramento dos internos nos pavilhões e casas ao cair da noite, o silêncio e a escuridão, traduzem o sentimento gerido na paisagem de

cotidianamente. As denominações fazem referência a personagens bíblicos, considerando a associação entre lepra e passagens bíblicas efetuada pelos ex-internos ao longo das entrevistas.

${ }^{6}$ Entrevista realizada em julho de 2014, na Vila Santo Antônio do Prata, município de Igarapé-Açu (Pará). 
controle da instituição, que nem a luz do dia consegue sanar, gerando o contraste apontado pelo/a autor/a do hino.

No entanto não são poucas as histórias de burla às normas. Uma delas diz respeito às inúmeras informações sobre pessoas em estado de embriaguez e o correspondente encarceramento. Nesse caso, a trajetória de Miriam ilustra as reapropriações que os internos faziam do espaço de controle do Leprosário. De acordo com o prontuário de Miriam, a paciente "evadiu-se" do Prata por duas vezes, em 1960 e 1968. Entre 1967 e 1968, ela foi presa duas vezes. Na primeira, por ter sido surpreendida "namorando com um sadio, em um dos pavilhões". No ano seguinte, foi "encontrada fora de hora perambulando (...) com o amante embriagado" (Prata, 1954:2). O uso de bebidas alcoólicas era proibido, mas, segundo os interlocutores, havia a possibilidade de acessá-las a partir dos internos que saíam à noite para efetuar sua compra. Chegando ao Prata, a bebida era escondida nas margens do rio, ou ainda em frascos feitos com bambu. Em outras instituições do mesmo tipo, de fato, a proibição no uso do álcool coabitava com as fugas e/ou "tráfico" de bebida para o interior dos leprosários (Silva, 2009).

Ao lembrar-se do excessivo controle ao qual eram submetidos os internos, Jó faz alusão às celas existentes no Pavilhão D, dizendo: “Chegava uma pessoa embriagada, ia preso!”. Provavelmente, após a fuga e uso de álcool, Miriam e seu companheiro ocuparam uma das celas destinadas aos "indisciplinados" (Souza Araujo, 1924:118). Jó relembra que um desses espaços era o mais temido pelos internos. Conhecida como "cela de sal", não possuía janelas e havia apenas uma entrada; a denominação do cômodo é referência ao "salgamento" das suas paredes, teto e chão. Segundo o interlocutor, os internos reincidentes nas contravenções previstas no estatuto da Colônia, ou mesmo os que desagradavam o diretor, eram colocados por longos períodos nesse local. O sal, associado ao calor e baixa circulação de ar, podia levar o doente à loucura ou à morte. A fuga estava dentre as infrações que mais levavam internos à "cela de sal".

No caso de Miriam, "namorar com um sadio", além de ser proibido pelo regulamento da Lazarópolis do Prata, pode ter aumentado a sua "pena", caso ela fosse casada no período. O mesmo pode ser dito sobre o fato de circular "fora de hora" junto com o "amante embriagado". O controle sobre a moral dos doentes era uma das regras máximas da instituição (Souza Araujo, 1924), o que faz pensar que o discurso moralizante deve ter pesado sobre a mulher casada que não respeitou os espaços e horários pré-determinados pela administração da Colônia.

Na década de 1970 Miriam teve seus quatro filhos dentro do Prata. As crianças nascidas nos leprosários eram confiscadas dos pais e levadas a preventórios em outras cidades, onde deveriam ser educadas e, eventualmente, recebiam visitas controladas (Monteiro, 1998). Hoje, Miriam vive sob cuidados de seus filhos, que retornaram ao Prata após o fechamento das atividades do Leprosário. Segundo a interlocutora, raramente sai da casa em que mora desde seu último casamento, a não ser para receber atendimentos médicos ou ir ao banco. Quem também permanece no Prata é o personagem do início desta seção. Jó não possui filhos e, segundo informações de terceiros, jamais casou. Por conta da idade avançada, recebe atenção de cuidadores particulares, pois deixou de morar no novo abrigo, onde continuam a residir alguns poucos exinternos.

O abrigo supracitado, segundo informações da última diretora, Irmã Neide Mühlbauer, é a casa de 11 ex-internos que recebem atendimento via Secretaria de Estado de Saúde do Pará (SESPA). Tais pessoas perderam os laços familiares externos à instituição, e, por isso, necessitam viver na unidade. Esses prédios foram construídos às margens dos Pavilhões Modernos, demolidos em data não informada pelos 
interlocutores. A atual Vila, porém, possui ao menos outros 60 ex-internos e suas famílias, morando nas casas da antiga instituição ou em outras edificações. Nas falas dessas pessoas existe marcada diferença frente aos moradores que não foram internos. Os ex-internos se afirmam como construtores da Vila do Prata, e é recorrente entre eles o lamento quanto ao que eles classificam como "abandono" do lugar.

\section{CONCLUSÃO}

A síntese da conformação da atual Vila Santo Antônio do Prata pode ser descrita pela sucessão de instituições construídas para implementar as diferentes políticas de Estado, inicialmente direcionadas aos Tembé, e, em seguida, a outros grupos marginalizados, indesejados ao convívio social. Obviamente, o Estado brasileiro possuiu redirecionamentos nas políticas de atenção à Vila, primeiro subsidiando a administração local e os moradores e depois reduzindo sua atuação no fornecimento de serviços públicos. Todavia há uma característica comum a tal sequência institucional: a reunião por longos períodos de significativo número de indivíduos de mesma situação social, formalmente administrados na totalidade de suas vidas (Goffman, 1974). Tal sucessão de instituições totais diz respeito ao investimento político no corpo dos sujeitos internados e na intricada relação de poder entre internos e administração institucional (Foucault, 1977). No estado do Amazonas, o leprosário de Paricatuba assumiu características semelhantes no que diz respeito à sequência de instituições disciplinares (Rebouças, 2013).

O funcionamento do Núcleo Colonial Indígena, entre 1898 e 1921, foi preponderante na política de homogeneização do povo Tembé, na medida em que submeteu as crianças indígenas aos educandários dirigidos por padres Capuchos (Fernandes, 2015; Beltrão, 2012). A tecnologia de controle dos corpos, que tinha como epicentro tais Institutos educacionais, espraiou-se sobre o Vale do rio Maracanã, visando atender aos interesses geopolíticos para a região (Lopes, 2016).

Do mesmo modo, a longa existência da Lazarópolis do Prata, entre 1921 e 1980, consolidou tanto a política de exclusão de doentes de hanseníase, quanto difundiu o imaginário sobre a lepra na região nordeste do estado do Pará. Não por acaso, até os dias atuais, o lugar é reconhecido pelos moradores do entorno como leprosário. Ao lado disso, os ex-internos continuam a reproduzir categorias explicativas forjadas no tempo do isolamento compulsório.

Se no passado os espaços construídos do Prata eram a edificação da presença arbitrária do Estado, hoje eles são símbolos da sua ausência. As construções, muitas em ruínas, parecem como fantasmas em meio à dinâmica do lugar. Os antigos internos, sejam eles indígenas ou ex-portadores de hanseníase, descrevem o arruinamento com pesar, associando-o ao descaso governamental. Esse é o caso do antigo cemitério, construído ainda no século XIX e em uso até o início da década de 1920, transformado em pasto e, mais recentemente, em área de extração de areia para construção civil, com a completa destruição dos túmulos (Lopes \& Beltrão, 2017).

Os usos diversos dos outros prédios, em arruinamento ou não, continuam a estabelecer vínculos com as experiências diárias dos moradores do Prata. Assim, a paisagem construída outrora é incorporada aos discursos cotidianos, em grande parte como alusões ao passado que, por vezes, é lembrado como pujante ou aterrorizante. 


\section{AGRADECIMENTOS}

Este artigo é parte da tese de doutorado do autor, orientada pela Prof ${ }^{a}$ Dr $^{a}$ Denise Pahl Schaan, no Programa de Pós-Graduação em Antropologia (PPGA) da Universidade Federal do Pará (UFPA). Com apoio de bolsa da CAPES, a investigação foi desenvolvida no âmbito dos projetos de pesquisa "Antropologias em Histórias Tembé/Tenetehara 'em suspenso'. Pertenças ocultas e 'etnogêneses’ identitárias como faces de etnocídio 'cordial' no rio Guamá (PA)”, coordenado pela Prof a . Dra . Jane Felipe Beltrão, e “Tempos, espaços e cultura material na Colônia Santo Antônio do Prata: Arqueologia Tembé/Tenetehara”, sob coordenação da orientadora da tese, ambos com financionamento do CNPq. 


\section{REFERENCIAS BIBLIOGRÁFICAS}

ALMEIDA, B. L. C. de. 2007. A profilaxia da Lepra no estado do Pará: o contexto da fundação da Lazarópolis do Prata (1920-1925). 55f. Monografia (Graduação em História), Faculdade de História, Universidade Federal do Pará, Belém.

BARRETO, J.; GASPARONI, J. M.; POLITANI, A. L.; REZENDE, L. M. d.; EDILON, T. S.; FERNANDES, V. G. \& LIM, V. M. 2013. Hanseníase e estigma. Hansenologia Internationalis, vol. 38, n. 1-2:14-25. Bauru.

BELTRÃO, J. F. 2012. Histórias 'em suspenso': os Tembé 'de Santa Maria', estratégias de enfrentamento do etnocídio 'cordial’. Revista História Hoje, vol. 1, n. 2:195-212. São Paulo.

BELTRÃO, J. F. \& Lopes, R. C. d. S.. 2014. Diásporas, homogeneidades e pertenças entre os Tembé Tenetehara de Santa Maria. ACENO, vol. 1. n. 1:123-143. Cuiabá.

BLANTON, R. E. 1994. House and households - A comparative study. Plenum Press, New York/London.

CABRAL, D. 2013. Lepra, medicina e políticas de saúde no Brasil (1894-1934). Coleção História e Saúde. Editora Fiocruz, Rio de Janeiro.

CÂMARA, C. S. 2009. O começo e o fim do mundo: estigmatização e exclusão social de internos da colônia do Bonfim. 147f. Dissertação (Mestrado em Ciências Sociais), Programa de Pós-Graduação em Ciências Sociais, Universidade Federal do Maranhão, São Luis.

CHING, D. K. 2010. Dicionário visual de arquitetura. Editora WMF Martins Fontes, São Paulo.

DUCATTI, I. 2007. Discurso científico e legitimação política: hanseníase e isolamento compulsório (Brasil, século XX). Projeto História, vol. 34:303-315. São Paulo.

FERNANDES, R. d. F. 2015. Tembé Tenetehara de Santa Maria do Pará: Retomando os fios da história. Estudos Amazônicos, vol. XIII, n. 1:214-249. Belém.

FLEXNER, J. L. 2012. An Institution that was a Village: Archaeology and Social Life in the Hansen's Disease Settlement at Kalawao, Moloka'i, Hawaii. Int. J. Histor. Archaeol., vol. 16:135-163.

FOUCAULT, M. 1977. Vigiar e Punir. Vozes, Petrópolis.

FOUCAULT, M. 1978. História da Loucura. Perspectiva, São Paulo.

FOUCAULT, M. 1979. Microfísica do poder. Edições Graal, Rio de Janeiro.

FRENCH, D. E. 1995. Ideology, politics and power: the socio-historical of the Archaeology of the D'Arcy Island Leper Colony, 1891-1924. 270f. Tese (Doutorado em Antropologia), Faculty of Graduate Studies, The University of British Columbia, Vancouver.

GOFFMAN, E. 1974. Manicômios, prisões e conventos. Editora Perspectiva, São Paulo.

HENRIQUE, M. C. 2012. Escravos no purgatório: o leprosário do Tucunduba (Pará, século XIX). História, Ciências, Saúde - Manguinhos, vol. 19 (supl.):53-177. Rio de Janeiro.

HILliER, B. \& HANSON, J. 1984. The Social Logic of Space. Cambridge University Press, Cambridge.

HILLIER, B.; HANSON, J. \& GRAHAM, H. 1987. Ideas are in things: an application of the space syntax method to discovering genotypes. Environment and Planning B: Planning and design, vol. 14:363-385.

HOCHMAN, G. 1993. Regulando os Efeitos da Interdependência: sobre as relações entre saúde pública e construção do Estado (Brasil 1910-1930). Estudos históricos, vol. 6 , n. 11:40-61. Rio de Janeiro.

KAMP, K. A. 1993. Towards an Archaeology of Architecture: clues from a modern Syrian village. Journal of Anthropological Research, vol. 49, n. 4:293-317. Chicago. 
LACERDA, F. G. 2010. Vida cotidiana em núcleos coloniais do Pará na virada do século XIX para o século XX. In CANCElA, C. D. \& CHAmbOuleyron, R. (Org.). Migrações na Amazônia. Editora Açaí, Belém. Pp. 6780 .

LEANDRO, J. A. 2013. Em prol do sacrifício do isolamento: lepra e filantropia na Argentina e no Brasil, 1930 1946. História, Ciências, Saúde - Manguinhos, vol. 20, n. 2:913-938. Rio de Janeiro.

LEONE, M. P. \& POTTER Jr, P. B. 1988. The recovery fo meaning: Historical Archaeology in eastern United States. Smithsonian Institute Press, Washington.

LOPES, R. C. d. S. 2017. Tempos, espaços e cultura material na Vila Santo Antônio do Prata, Pará - Arqueologia em uma instituição total amazônica. 170f. Tese (Doutorado em Antropologia), Programa de Pós-Graduação em Antropologia, Universidade Federal do Pará, Belém.

LOPES, R. C. d. S. 2016. Políticas indigenistas na Amazônia e a resistência étnica dos Tembé/Tenetehara de Santa Maria do Pará, Amazônia brasileira. Espaço Ameríndio, vol. 10, n. 2: 162-193. Porto Alegre.

LOPES, R. C. d. S.. 2015. Os Tembé/Tenetehara de Santa Maria do Pará: entre representações e diálogos antropológicos. Iluminuras, vol. 16, n. 38:219-254. Porto Alegre.

LOPES, R. C. d. S. \& BELTRÃO, J. F. 2017. Patrimônio histórico e memória social: entre indígenas e exinternos na Vila Santo Antônio do Prata, Amazônia brasileira. ContraCorrente, Revista de Estudos Literários e da Cultura, vol. 9, n. 9:1-15. Manaus.

LOPES, R. C. d. S. \& SCHAAN, D. P. 2016. Projeto arqueológico Vila Santo Antônio do Prata, Igarapé-Açu (PA)Relatório final. Núcleo de Pesquisa e Ensino em Arqueologia/Programa de Pós-Graduação em Antropologia Universidade Federal do Pará, Belém.

LOPES, R. C. d. S.. 2015. Projeto arqueológico Vila Santo Antônio do Prata, Igarapé-Açu (PA) - $2^{\circ}$ relatório parcial. Núcleo de Pesquisa e Ensino em Arqueologia/Programa de Pós-Graduação em Antropologia Universidade Federal do Pará, Belém.

MACHADO, R.; LOUREIRO A.; LUZ, R. \& MURICY, K. 1978. Danação da norma: medicina social e constituição da psiquiatria no Brasil. Vol. 3. Saber e Sociedade. Edições Graal, Rio de Janeiro.

MONTEIRO, Y. N. 2003. Prophylaxis and exclusion: compulsory isolation of Hansen's disease patients in São Paulo. História, Ciências, Saúde - Manguinhos, vol. 10 (Suplemento):95-12. Rio de Janeiro.

MONTEIRO, Y. N.. 1998. Violência e profilaxia: os preventórios paulistas para os filhos de portadores de hanseníase. Saúde e Sociedade, vol. 7, n. 1:3-26. São Paulo.

MOREIRA, J. M. B. \& SOARES, F. C. 2015. Muralhas que comunicam: fortificações catarinenses como portais de acesso ao Brasil Meridional. In SOARES, F. C. (Org.). Arqueologia das fortificações: perspectivas. Lagoa, Florianópolis. Pp. 101-148.

MUNIZ, P. 1913. O Instituto do Prata (Município de Igarapé-Assú). Typ. da Livraria Escolar, Belém.

NAJJAR, R. 2011. Para além dos cacos: a Arqueologia Histórica a partir de três superartefatos (estudo de caso de três igrejas jesuíticas). Boletim do Museu Paraense Emilio Goeldi. Ciências Humanas, vol. 6, n. 1:71-91. Belém.

PRATA, Colônia do. 1954-. Prontuários da Colônia Santo Antônio do Prata.

REBOUÇAS, J. Q. 2013. Paricatuba: um monumento arqueológico de caráter histórico. 30f. Trabalho de Conclusão de Curso (Graduação em Arqueologia), Faculdade Arqueologia, Universidade do Estado do Amazonas, Iranduba.

SERIQUE, R. V. X. 2015. Espaço Educandário: Análise Histórica, Arquitetônica e Proposta de refuncionalização do antigo prédio em Santo Antônio do Prata, PA. Trabalho de Conclusão de Curso (Graduação em Arquitetura), Faculdade de Arquitetura e Urbanismo, Universidade Federal do Pará, Belém.

SILVA, J. B. d. 2009. A ex-colônia de hansenianos de Marituba: perspectivas histórica, sociológica e etnográfica. Paper NAEA,vol. 234: 1-43. Belém. 
SOUZA ARAUJO, H. C. d. 1948. História da lepra no Brasil - Período republicano (1889-1946). Vol. II. Imprensa Nacional, Rio de Janeiro.

SOUZA ARAUJO, H. C. d. 1924. Lazaropolis do Prata: a primeira colonia agrícola de leprosos fundada no Brasil. Empreza Graphica Amazonia, Belém.

STEADMAN, S. R. 1996. Recent research in the archaeology of architecture: beyond the foundations. Journal of Archaeological Research, vol. 4, n. 1:51-93.

STEPAN, N.L. 2004. Eugenia no Brasil, 1917-1940. In HOCHMAN, G. \& ARMUS, D. (Orgs.). Cuidar, controlar, curar: ensaios históricos sobre saúde e doença na América Latina e Caribe. Editora FIOCRUZ, Rio de Janeiro. Pp. 330-391.

ZARANKIN, A. 2008. Los guardiones del capital: arqueologia de la arquitectura de los bancos de Buenos Aires. In ACUTO, F. A. \& ZARANKIN, A. Sed non Satita II: acercamientos sociales em La arqueologia latino-americana. Encuentro Grupo Editor Editado, Córdoba. Pp. 325-339.

ZARANKIN, A. 2005. "Walls of Domestication". Archaeology of the architecture of capitalist elementary public schools; The case of Buenos Aires. In FUNARI, P. P.; ZARANKIN, A. \& STOVEL, E. (Orgs.) Global Archaeological Theory: contextual voices and contemporary thoughts. Kluwer-Plenum, New York. Pp. 237-264.

ZARANKIN, A. 2001. Paredes que domesticam: arqueologia da arquitetura escolar capitalista: o caso de Buenos Aires. $255 f$. Tese (Doutorado em História), Programa de Pós-Graduação em História, Universidade de Campinas, Campinas.

ZARANKIN, A. 1999. Arqueología de la arquitectura: another brick in the wall. Revista do Museu de Arqueologia e Etnologia da Universidade de São Paulo, vol. 3:119-129. São Paulo.

ZARANKIN, A. \& NIRO, C. 2010. A materialização do sadismo: arqueologia da arquitetura dos centros clandestinos de detenção da ditadura militar argentina (1976-1983). Revista Internacional de Direito e Cidadania, vol. 6:17-32. São Paulo. 